\title{
Offensive, Defensive, and Generic Advertising Strategies in a Dynamic Oligopolistic Market
}

\author{
Mostafa Jafari $(\mathbb{D}$, Mohammad Mohammadpour omran, and Ehsan Jahani \\ Department of Industrial Engineering, Iran University of Science \& Technology, Tehran, Iran \\ Correspondence should be addressed to Mostafa Jafari; jafari@iust.ac.ir
}

Received 15 November 2020; Revised 20 January 2021; Accepted 6 March 2021; Published 7 April 2021

Academic Editor: Arunava Majumder

Copyright ( 92021 Mostafa Jafari et al. This is an open access article distributed under the Creative Commons Attribution License, which permits unrestricted use, distribution, and reproduction in any medium, provided the original work is properly cited.

\begin{abstract}
In today's highly competitive business environment, advertisement plays an influential role in attracting customers and increasing market share. Companies adopt different advertising strategies in a competitive market, such as offensive, defensive, and generic, to keep and increase their market share. Researchers have generally modeled this problem using a dynamic differential game. All previous research studies have focused on finding these strategies in a duopoly market. Also, to simultaneously determine the optimal equilibrium strategy for these three strategies, the model is designed as a symmetric game due to the ease of solving. In contrast with the previous researches, the purpose of this paper is to present and solve an asymmetric game model to determine the optimal offensive, defensive, and generic advertising strategies in an oligopoly market. The proposed model's objective is to obtain the maximum equilibrium profit for each company at any moment regarding the market share of each company and those of competitors. A numerical solution method based on the Pontryagin's maximum principle is developed to solve the model. Then, the proposed model is solved for a triopoly market. Also, the sensitivity of the results to changes in model parameters has been investigated. The obtained results denote that in markets with more than two players under the asymmetric game, the proposed model can prescribe the optimal type of offensive, defensive, and generic advertising strategies.
\end{abstract}

\section{Introduction}

Marketing managers generally try to spend their budget optimally and with maximum effectiveness to strengthen their company's competitive position $[1,2]$. In this regard, one of the challenges facing marketing managers is changes in marketing strategies and the market share of different competitors over time [3-5]. In this case, a marketing manager has to make his budget decisions dynamically over time and based on market changes [6]. A fixed strategy for the decision time horizon leads to huge losses, so researchers have generally modeled this problem using dynamic differential games.

Moreover, marketing managers face three advertising strategies to adopt: offensive, defensive, and generic strategies. For a company with a wide variety of customers, defensive advertising is suggested. In this strategy, there is no need to make a considerable attempt to attract customers' attention to their goods/services; thus, advertising is expected to increase retention and improve current customers' loyalty. In offensive advertising, companies seek to attract customers of their competitors. To this end, they run advertisements in which they emphasize their strengths and the weaknesses of competitors. In the third marketing strategy, companies try to emphasize the competitive advantage of their products/services for potential customers across the chosen market scope. For example, in recent years, three online taxi companies, namely, Snapp, Tap30, and Carpino, have operated in public transportation in Iran. To keep and increase the market share, these companies have adopted a different type of defensive, offensive, and generic advertising strategy. The first company which entered the online taxi market in Iran was Snapp, and after that, Tap30 and Carpino entered this market. In Table 1, different types of offensive, defensive, and generic marketing strategies, which are adopted by these companies, are demonstrated.

Despite the widespread use of offensive, defensive, and public advertising strategies by companies, there is little 
TABle 1: Offensive, defensive, and generic advertising strategies of three online taxi services in Iran.

$\begin{array}{cccc}\text { Snapp } & \text { Tap30 } & \text { Carpino } & \text { Generic } \\ \text { Defensive } & \text { Offensive } & \text { Offensive } & \end{array}$

(1) Providing high-quality transportation service

(1) Quick access in the shortest possible time (2) Not enough knowledge about using smartphones

(3) High ranking drivers

(4) The smartest online taxi application

\section{Offensive}

(1) The ability of trip Tap30 sharing

(2) Providing lower price transportation services Offensive
(1) Drivers with higher quality services

(2) Recruiting resident drivers in each city
(1) Not enough knowledge about the application

(2) Drivers' low education level

(3) Long distance from drivers to passengers

(4) The high price of transportation service

Offensive

(1) Providing taxi services

for all destinations with

the lowest price

(2) Instant payment with a debit card

Offensive

(1) Safety for women and

Carpino girls all the time

(2) Accessibility all the time in bad weather conditions
Defensive

(1) Drivers with valid driving license and regular medical test conformed by taxi organization

(2) "I am responsible" campaign

(represents high responsibility of Carpino drivers for passengers
(2) Giving score and comment to drivers

(3) Finding the nearest taxi around and directs it to the passengers

(4) High security

(5) Monitoring and sending the instant location to the others

(6) Getting the lowest price service in comparison to traditional transportation structure research on them, especially in a competitive environment. The only existing research, which has modeled all three advertising approaches in conflict situations and the form of a dynamic differential game, is Jørgensen and Sigué [7] paper. Due to the complexity of solving differential game models by considering more than two players, this paper's proposed model is designed as a duopoly. Although some cases can be mentioned, considering only two players in modeling this issue is an unrealistic condition. In practice, in today's competitive world, the number of competing companies in a particular business is more than two. In addition, the offensive, defensive, and general equilibrium advertising strategy in an asymmetric game has not been investigated so far. According to the mentioned research gap, the purpose of this paper is to present and solve a model that explains the advertising competition between more than two players in an asymmetric dynamic advertising differential game by considering offensive, defensive, and generic advertising strategies.

The rest of the paper is organized as follows. Section 2 presents the related review of the literature. Section 3 presents the mathematical model formulation. Section 4 presents the numerical solution approach. In Section 5, the proposed model for a triopoly market has been presented and solved, and Section 6 concludes.

\section{Literature Review}

Despite the use of dynamic game models in different parts of the supply chain by many researchers $[3,8,9]$, a handful of papers in which the competitive and dynamic business environment is considered in a differential game. For the first time, Erickson [10] proposed an offensive and defensive marketing strategy model under a dynamic competitive environment. In this study, Erickson developed the Lanchester model by considering offensive and defensive strategies and provided a closed-loop solution methodology to obtain the closed-form solution. In this model, the increase in market share is defined in proportion to the ratio of offensive advertising efforts to defensive. He has used the Pontryagin's maximum principle to solve the proposed model. From a different perspective, Martín-Herrán et al. [11] investigated the dynamics of market share conditions under offensive and defensive strategies. In this model, changes in the market share of the 1st company have a linear relationship with his offensive advertising efforts and competitor's defensive efforts, designed based on the Lanchester model. For solving the proposed model, Hamilton-Jacobi-Bellman equations have been utilized for a closed-loop solution method to obtain a closed-form solution. Similar to the proposed model by Martín-Herrán et al. [11], Jørgensen and Sigué [7] proposed a 
linear model for generic advertising efforts, and the sales rate was advised as a state variable instead of a market share. In this model, offensive and defensive advertising efforts and changes in the sale rate for each are dependent on both companies' sum of advertising efforts. Using HamiltonJacobi-Bellman equations in an infinite time horizon, the model was solved in a closed-loop way, and a closed-form solution was provided. In another study, Machowska [12] added the potential market share rate to the dynamic advertising model's state equation. In this model, market share is equal to the total market share minus the competitor's market share plus the rate of potential market share. For the proposed model, under symmetric information situation, that is the same parameters for both companies, a closed-loop solution is provided using Pontryagin's maximum principle. From a relatively new perspective, based on the Nerlove-Arrow model, Machowska and Nowakowski [13] proposed a goodwill model in which offensive and defensive advertising variables along with customer recommendation were considered in a segmented market. Due to the proposed model's complexity, a numerical solution algorithm designed based on the dynamic duopoly game and Hamilton-Jacobi-Bellman equations were employed under open-loop Nash equilibrium.

Table 2 demonstrates the important features of relevant papers in detail. One of the common features between these studies is considering of offensive and defensive advertising approach under duopoly. The main reason is that under an oligopoly market structure, there is a dependency on more than one state variable (such as market share and quality in Erickson [14] and El Ouardighi et al. [15]). In such cases, to solve the model, there is a nonlinear model with partial differential equations, in which the number of equations is less than the decision (control) variables. Accordingly, obtaining a closed-form solution is almost impossible [15]. Nevertheless, there are many oligopolies in the real world, such as the automobile manufacturing industry, telecommunications companies, mobile phone service providers, airlines, pharmaceutical companies, and software companies that operate under offensive and defensive advertising policies. As a result, duopoly game models cannot be used for these market structures any longer. Therefore, it aims to address strategic marketing in an oligopoly model under the offensive, defensive, and generic advertising approach in the current study. This model is developed based on Jørgensen and Sigué [7] in oligopoly and asymmetric game. It should be noted that under asymmetric information, the value of model parameters varies from a player (company) to another. Inspired by Erickson [16], a closed-loop solution method is proposed based on the Pontryagin's maximum principle to solving the proposed model.

In the dynamic of state variables column, $M_{1}, S_{1}$, and $G_{1}$ are the market share, sales rate, and goodwill of firm 1, respectively. $a_{i}, d_{i}$, and $g_{i}$ are the offensive, defensive, and generic advertising strategies of firm $i$, respectively $(i=1,2)$. $\beta_{i}$ and $\lambda_{i}$ and $k$ are parameters of offensive, defensive, and generic strategies, respectively. $\delta_{i}$ is the goodwill depreciation rate of firm $i(i=1,2), \varepsilon$ is the potential market rate, $c$ is the segment parameter, and $\gamma_{i}$ is the customer judgment parameter of firm $i(i=1,2)$.

\section{Problem Definition}

Assume that several companies (more than two companies) with the same goods or services decide on the defensive, offensive, and generic advertising strategies in an oligopolistic market to maximize their profits. The decision-making process is carried out in a finite time horizon. Also, in modeling competition between companies, it is assumed that the games are asymmetric; that is, the parameters of the proposed model as well as the initial values for the state variable (the market share of the companies) for each company are different. In such a case, the market share of each of the companies evolves, according to equation (1) (Table 3 presents the parameters and variables used in this paper).

$$
\dot{M}_{i}=\sum_{\substack{j=1 \\ j \neq i}}^{N} G_{i}\left(a_{i}, d_{j}\right) M_{j}-\sum_{j=1}^{N} G_{j}\left(a_{j}, d_{i}\right) M_{i}+D\left(g_{i}(t), g_{-i}(t)\right)\left(1-\sum_{j=1}^{N} M_{j}\right), \quad \text { for } i=1, \ldots, N
$$

where $\dot{M}_{i}=(\mathrm{d} M / \mathrm{d} t), N$ is the number of companies, $M_{i} \geq 0$ is the market share of company $i$ (state variable), $a_{i}(t) \geq 0$ is the offensive advertising effort rate of company $i$ at time $t$, $d_{i}(t) \geq 0$ is the defensive advertising effort rate of company $i$ at time $t, g_{i}(t) \geq 0$ is the generic advertising effort rate of company $i$ at time $t, g_{-i}(t)$ is the total generic advertising effort rate of all companies other than $i, G_{i}\left(a_{i}, d_{j}\right)$ is the attraction rate function of company $i$, and $D\left(g_{i}(t), g_{-i}(t)\right)$ is the generic advertising effort rate function of company $i$. Companies use the generic advertising strategy to focus on a portion of the potential market that has not been covered so far (in this case, the total market share of the companies plus 


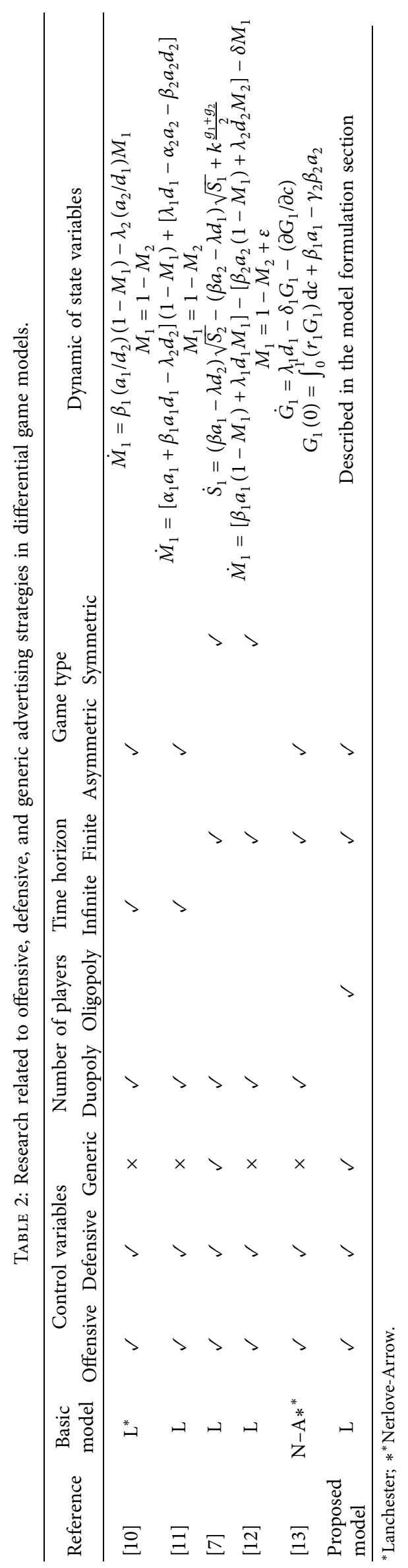


TABle 3: Nomenclature.

\begin{tabular}{|c|c|}
\hline Notation & Description \\
\hline $\bar{i}$ & Index of players (companies) \\
\hline$j$ & Index of players (companies) other than $i$ \\
\hline$N$ & Number of players (companies) \\
\hline$M_{i}$ & The market share of company $i$ \\
\hline$a_{i}(t)$ & The offensive advertising effort rate of company $i$ at time $t$ \\
\hline$d_{i}(t)$ & Defensive advertising effort rate of company $i$ at time $t$ \\
\hline$g_{i}(t)$ & The generic advertising effort rate of company $i$ at time $t$ \\
\hline$g_{-i}(t)$ & The total generic advertising effort rate of all companies other than $i$ \\
\hline$G_{i}\left(a_{i}, d_{j}\right)$ & The attraction rate function of company $i$ \\
\hline$D\left(g_{i}(t), g_{-i}(t)\right)$ & The generic advertising effort rate function of company $i$ \\
\hline$M_{u c}$ & The share that has not been covered yet \\
\hline$\beta_{i}$ & The offensive advertising constant of company $i$ \\
\hline$\lambda_{j}$ & The defensive advertising constant of company $j$ \\
\hline$l_{i}^{\prime}$ & The generic advertising constant of company $i$ \\
\hline$J_{i}\left(a_{i}, d_{i}, g_{i}\right)$ & Profit present value of $i$-th company when it uses $a_{i}, d_{i}$, and $g_{i}$ strategies \\
\hline$\pi_{i}$ & The marginal profit of company $i$ \\
\hline$V$ & The potential market \\
\hline$C_{a}\left(a_{i}(t)\right)$ & The offensive advertising cost function of company $i$ \\
\hline$C_{d}\left(d_{i}(t)\right)$ & The defensive advertising cost function of company $i$ \\
\hline$C_{g}\left(g_{i}(t)\right)$ & The generic advertising cost function of company $i$ \\
\hline$c_{a}$ & Constant parameter of offensive strategy \\
\hline$c_{d}$ & Constant parameter of defensive strategy \\
\hline$c_{g}$ & Constant parameter of generic strategy \\
\hline$T^{g}$ & The time horizon \\
\hline$x=\left(x_{1}, \ldots, x_{n}\right)$ & The vector of state variables \\
\hline$x_{i}(t)$ & The state variable of company I at time $t$ \\
\hline$u_{i}(x, t)$ & The control variable of company I in state $x$ and at time $\mathrm{t}$ \\
\hline$H_{i}$ & The Hamiltonian for company $i$ \\
\hline$k_{i j}$ & Costate variable \\
\hline$Z_{u_{i, k}}$ & The belief of the $i$-th company about the response of the $k$-th company to change in the state variable of the $j$-th company \\
\hline
\end{tabular}

the uncovered share is equal to one, i.e., $\sum_{i=1}^{N} M_{i}+M_{u c}=1$, where $M_{u c}$ is the share that has not been covered yet). The advertising effort rate functions are similar to those of Jørgensen and Sigué [7] and Martín-Herránet al. [11] but are defined asymmetrically as follows:

$$
\begin{gathered}
G_{i}\left(a_{i}, d_{j}\right)=\beta_{i} a_{i}-\lambda_{j} d_{j}, \quad i, j=1, \ldots, N, \\
D\left(g_{i}(t), g_{-i}(t)\right)=\frac{\left(l_{i} g_{i}+\sum_{\substack{j \neq 1 \\
j \neq i}}^{N} l_{j} g_{j}\right)}{N}, \quad i, j=1, \ldots, N,
\end{gathered}
$$

where $\beta_{i}$ is the offensive advertising constant of company $i$, $\lambda_{j}$ is the defensive advertising constant of company $j$, and $l_{i}$ is the generic advertising constant of company $i$. According to the three preceding equations, the changes in the market share of each company over time depend on the following factors:

(1) The offensive advertising effort of company $i$ to seize the market share of other companies and the defensive advertising effort of other companies to maintain their market share

(2) The offensive effort of other companies to grab the market share of company $i$ and the defensive effort of company $i$ to keep its market share
(3) The generic efforts of companies to increase the overall share of the market potential

Each company maximizes its present value of profit according to the following equation:

$$
\begin{aligned}
J_{i}\left(a_{i}, d_{i}, g_{i}\right)= & \int_{0}^{T}\left[\pi_{i} M_{i}(t) V-C_{a}\left(a_{i}(t)\right)-C_{d}\left(d_{i}(t)\right)\right. \\
& \left.-C_{g}\left(g_{i}(t)\right)\right] \mathrm{d} t, \quad \text { for } i=1, \ldots, N
\end{aligned}
$$

where $C_{a}\left(a_{i}(t)\right)$ is the offensive advertising cost function of company $i, C_{d}\left(d_{i}(t)\right)$ is the defensive advertising cost function of company $i, C_{g}\left(g_{i}(t)\right)$ is the generic advertising cost function of company $i, \pi_{i}$ is the marginal profit of company $i, V$ is the potential market, and $T$ is the time horizon. The advertising cost functions are the same as those of Jørgensen and Sigué [7] and are defined as follows:

$$
\begin{aligned}
& C_{a}\left(a_{i}\right)=\frac{c_{a}}{2} a_{i}^{2}, \\
& C_{d}\left(d_{i}\right)=\frac{c_{d}}{2} d_{i}^{2}, \\
& C_{g}\left(g_{i}\right)=\frac{c_{g}}{2} g_{i}^{2}, \quad i, j=1, \ldots, N,
\end{aligned}
$$




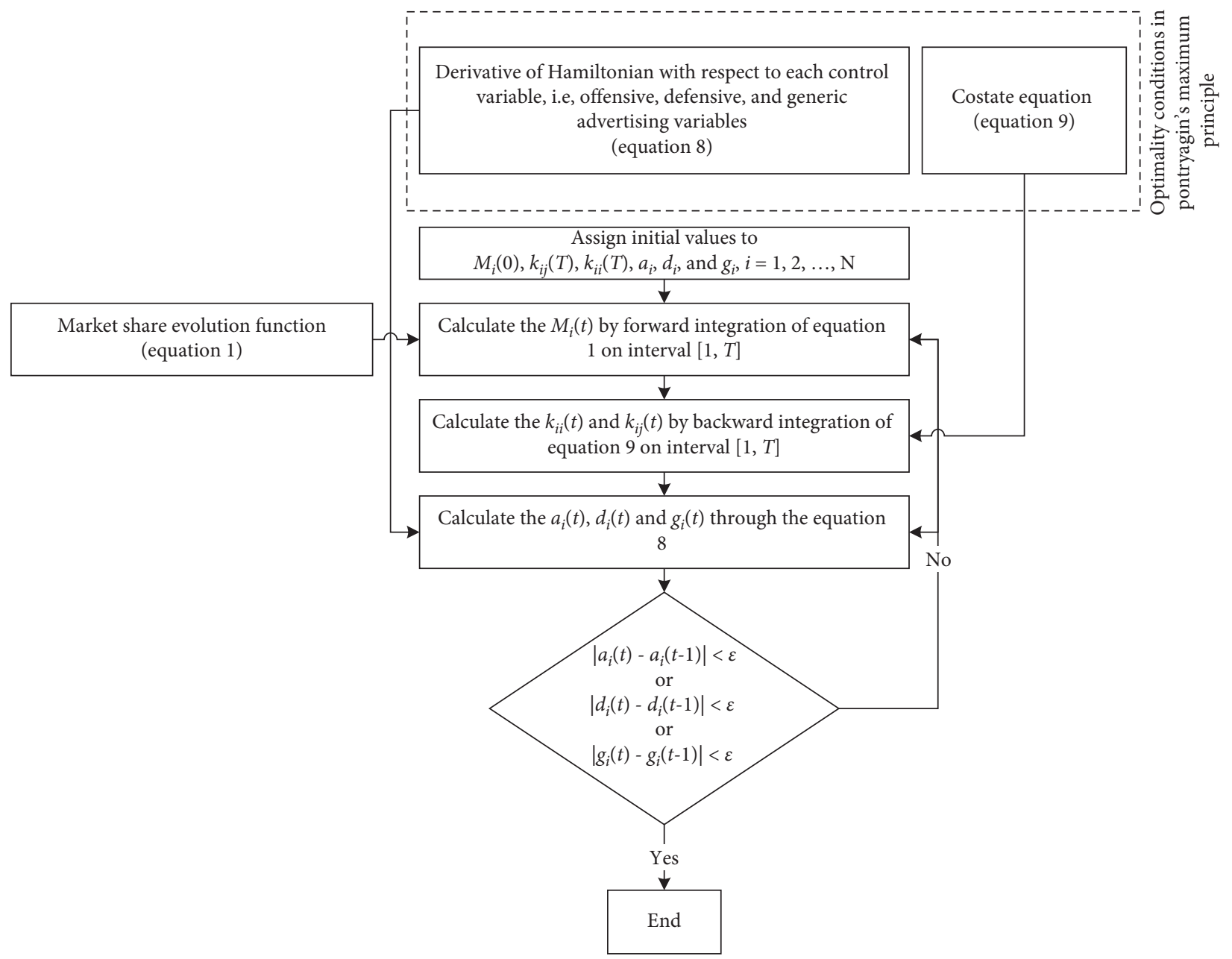

FIgURE 1: The process of the numerical solution.

where $c_{a}, c_{d}$, and $c_{g}$ are the constant parameters of offensive, defensive, and generic strategies, respectively. In the next section, the solution process is described.

\section{Solution Methodology}

The differential game problems and their solution methodologies date back to the late 1940s. For the first time, Isaacs [17] formulated a differential game model for military purposes (the missile pursuit-evasion game), which, for some reasons, was not published until 1965. The combination of Isaac's research and Bellman's research (in dynamic programming) with Pontryagin's research (in optimal control) has led to the establishment of the base of differential games [18]. Recent research on differential games has focused on the development of optimal control problems in solving these types of models [19]. The optimality conditions in Pontryagin's maximum principle for the following problem,

$$
\begin{array}{ll}
\max _{u_{i}} & J_{i}=\int_{0}^{T}\left(g\left(x_{i}(t), u_{1}(x, t), u_{2}(x, t), \ldots, u_{n}(x, t)\right)\right) \mathrm{d} t \\
\text { s.t. } & \dot{x}_{i}(t)=f_{i}\left(x_{i}(t), u_{1}(x, t), u_{2}(x, t), \ldots, u_{n}(x, t)\right), x_{i}\left(t_{0}\right)=x_{i 0} \text { for } i=1, \ldots, N,
\end{array}
$$

are defined as follows: 


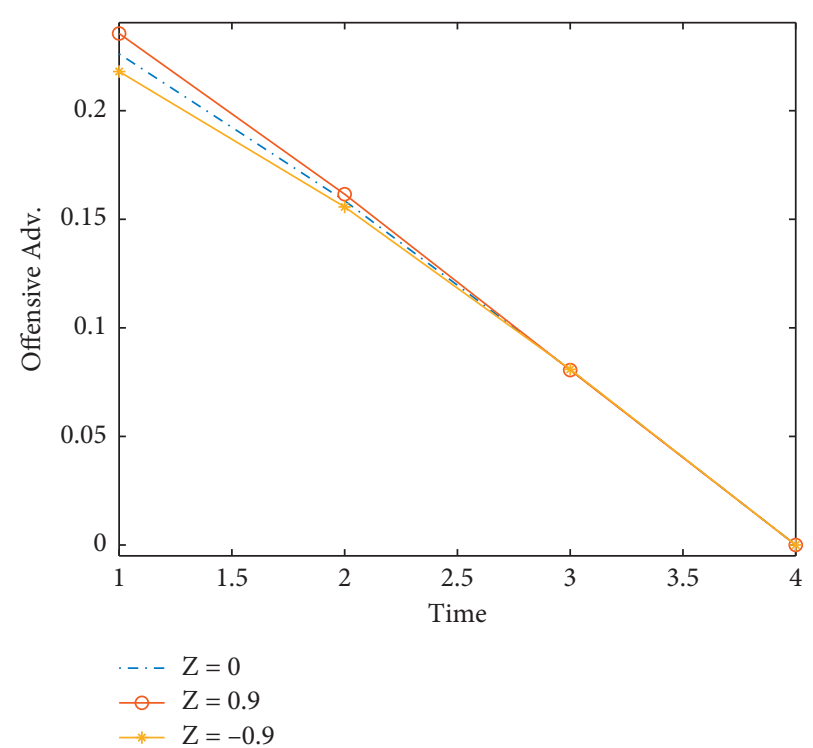

(a)

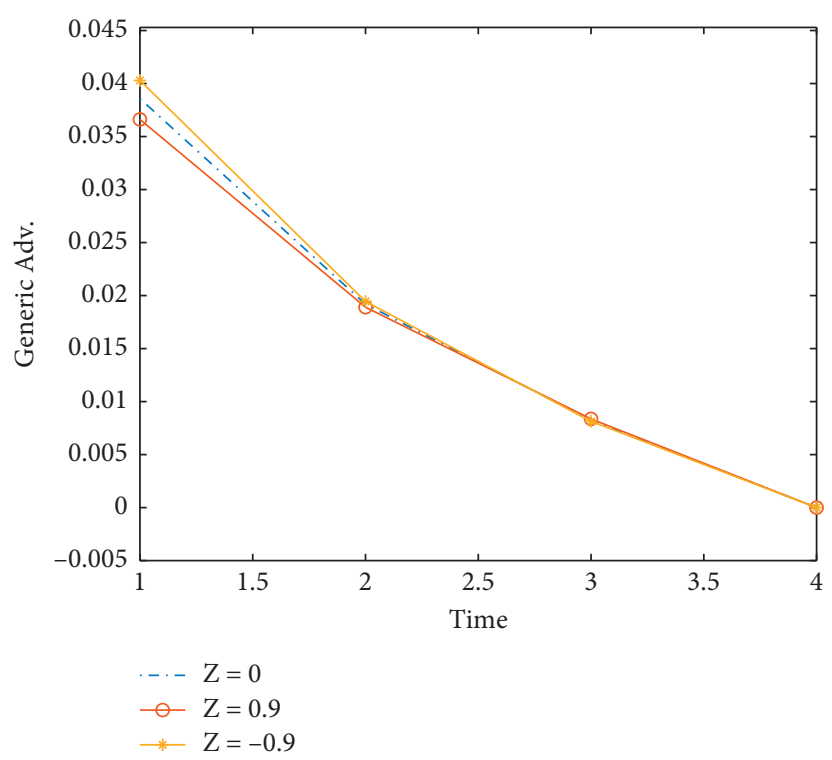

(c)

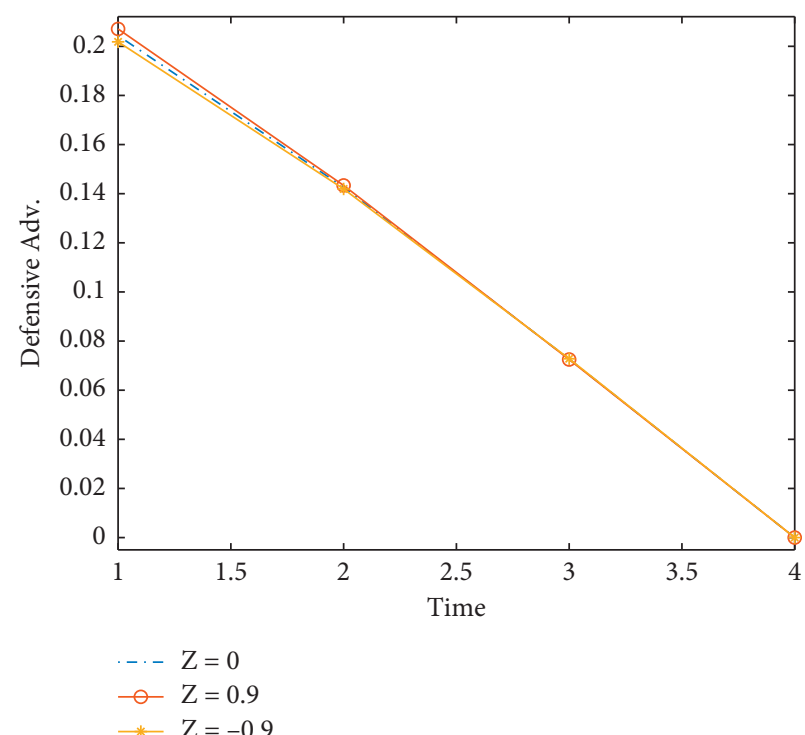

(b)

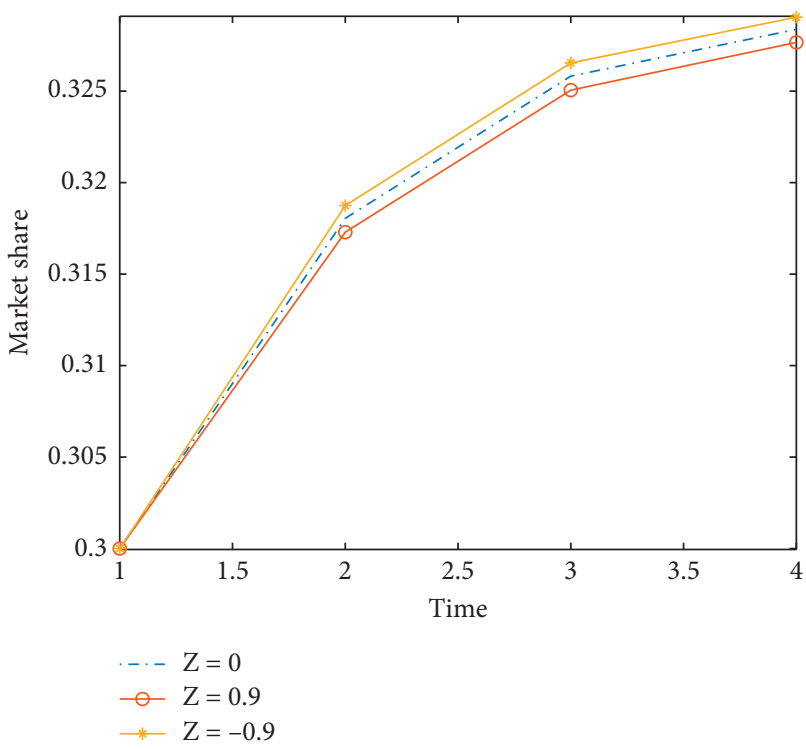

(d)

Figure 2: Equilibrium trajectories for offensive (a), defensive (b), and generic (c) strategies and market share (d) for company 1 in a hypothetical triopoly problem.

$$
\begin{aligned}
H_{i} & =\left(g\left(x(t), u_{1}(x, t), u_{2}(t), \ldots, u_{n}(t)\right)\right)+\sum_{j=1}^{N} k_{i j}\left(f_{i}\left(x_{i}(t), u_{1}(x, t), u_{2}(x, t), \ldots, u_{n}(x, t)\right)\right), \quad \text { for } i=1, \ldots, N, \\
\frac{\partial H_{i}}{\partial u_{i}} & =0, \quad \text { for } i=1, \ldots, N \\
\dot{k}_{i j} & =-\frac{\partial H_{i}}{\partial x_{i}}-\sum_{q=j}^{n} \frac{\partial H_{i}}{\partial u_{q}} \frac{\partial u_{q}}{\partial x_{j}}
\end{aligned}
$$

where $x=\left(x_{1}, \ldots, x_{n}\right)$ is the vector of state variables, $x_{i}$ is the state variable of company $i, u_{i}(x, t)$ is the control variable of company $i, H_{i}$ is the Hamiltonian defined for company $i$, and $k_{i j}$ is the costate variable or shadow price. In a feedback solution, the control variable $u$ depends on the state variable $x$. Therefore, in the dynamic equation of the costate variable 


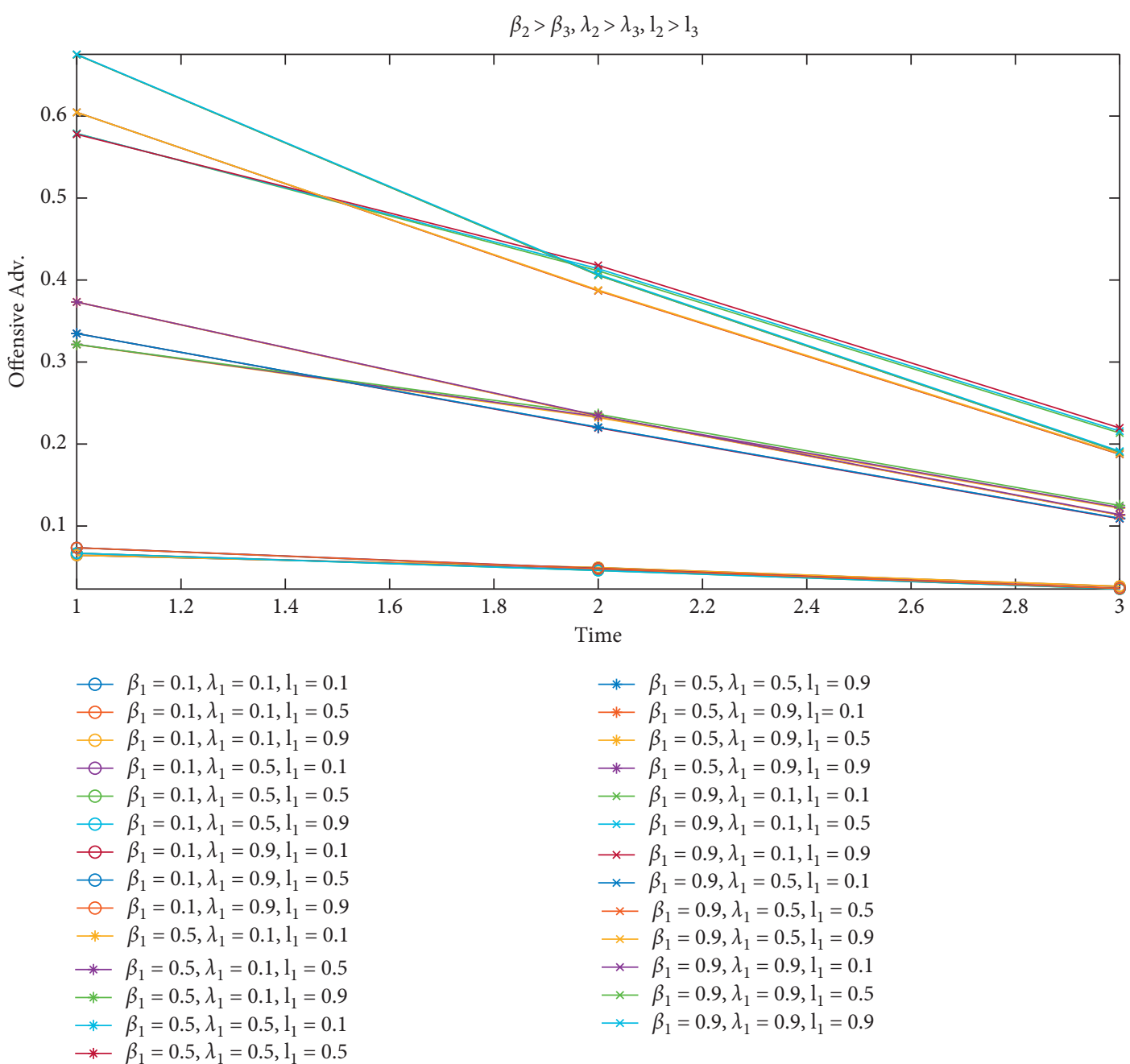

(a)

Figure 3: Continued. 


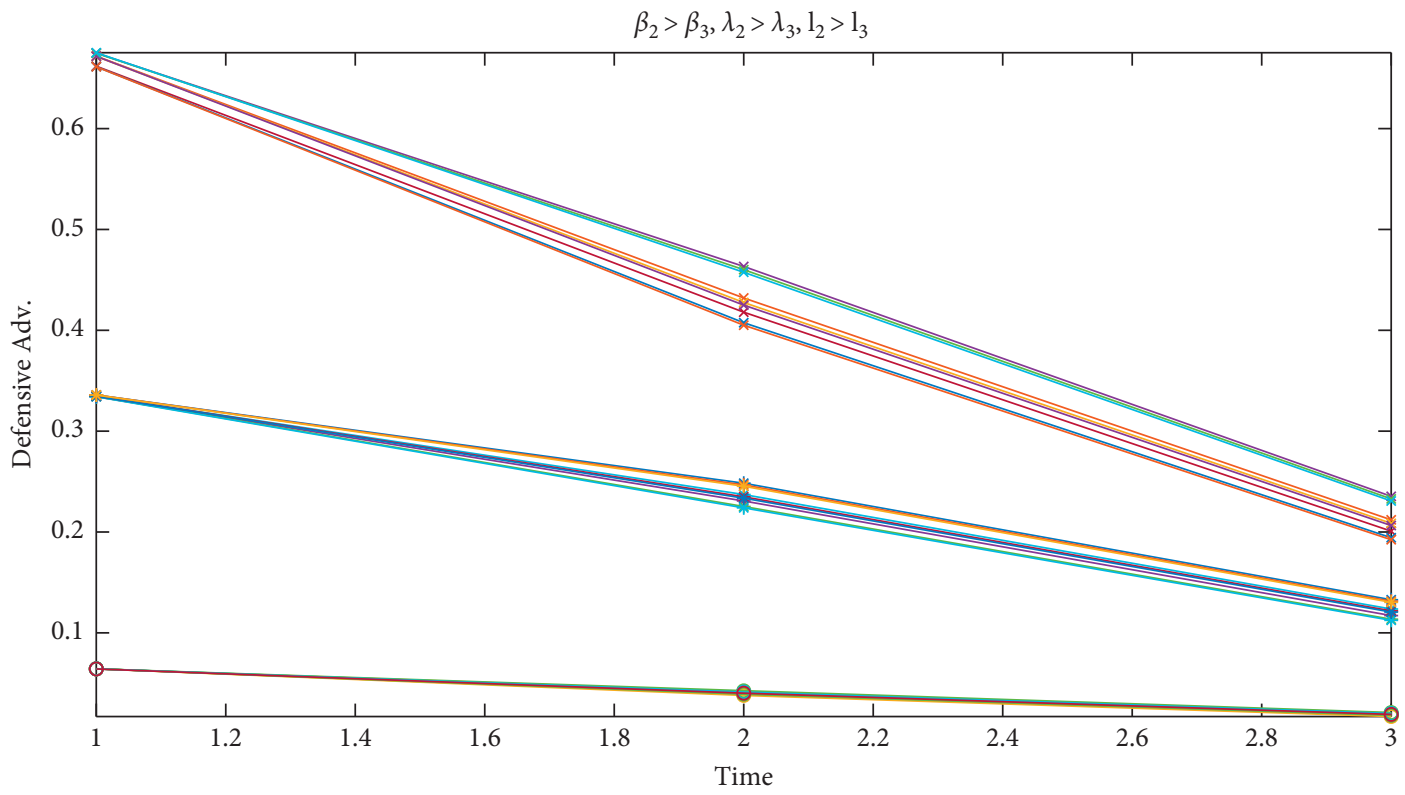

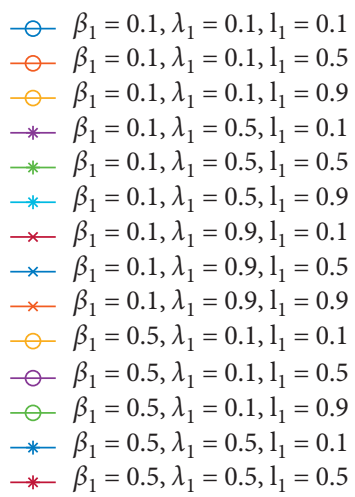

$\rightarrow \beta_{1}=0.5, \lambda_{1}=0.5,1_{1}=0.9$

$\star \beta_{1}=0.5, \lambda_{1}=0.9,1_{1}=0.1$

$\leftarrow \beta_{1}=0.5, \lambda_{1}=0.9,1_{1}=0.5$

$\approx \beta_{1}=0.5, \lambda_{1}=0.9,1_{1}=0.9$

$\circ \beta_{1}=0.9, \lambda_{1}=0.1,1_{1}=0.1$

$\frown \beta_{1}=0.9, \lambda_{1}=0.1,1_{1}=0.5$

$\bigcirc \beta_{1}=0.9, \lambda_{1}=0.1,1_{1}=0.9$

$* \beta_{1}=0.9, \lambda_{1}=0.5,1_{1}=0.1$

$\rightarrow \beta_{1}=0.9, \lambda_{1}=0.5,1_{1}=0.5$

$* \beta_{1}=0.9, \lambda_{1}=0.5,1_{1}=0.9$

$\star \beta_{1}=0.9, \lambda_{1}=0.9,1_{1}=0.1$

$\star \beta_{1}=0.9, \lambda_{1}=0.9,1_{1}=0.5$

$\leftarrow \beta_{1}=0.9, \lambda_{1}=0.9,1_{1}=0.9$

(b)

FIgURE 3: Continued. 


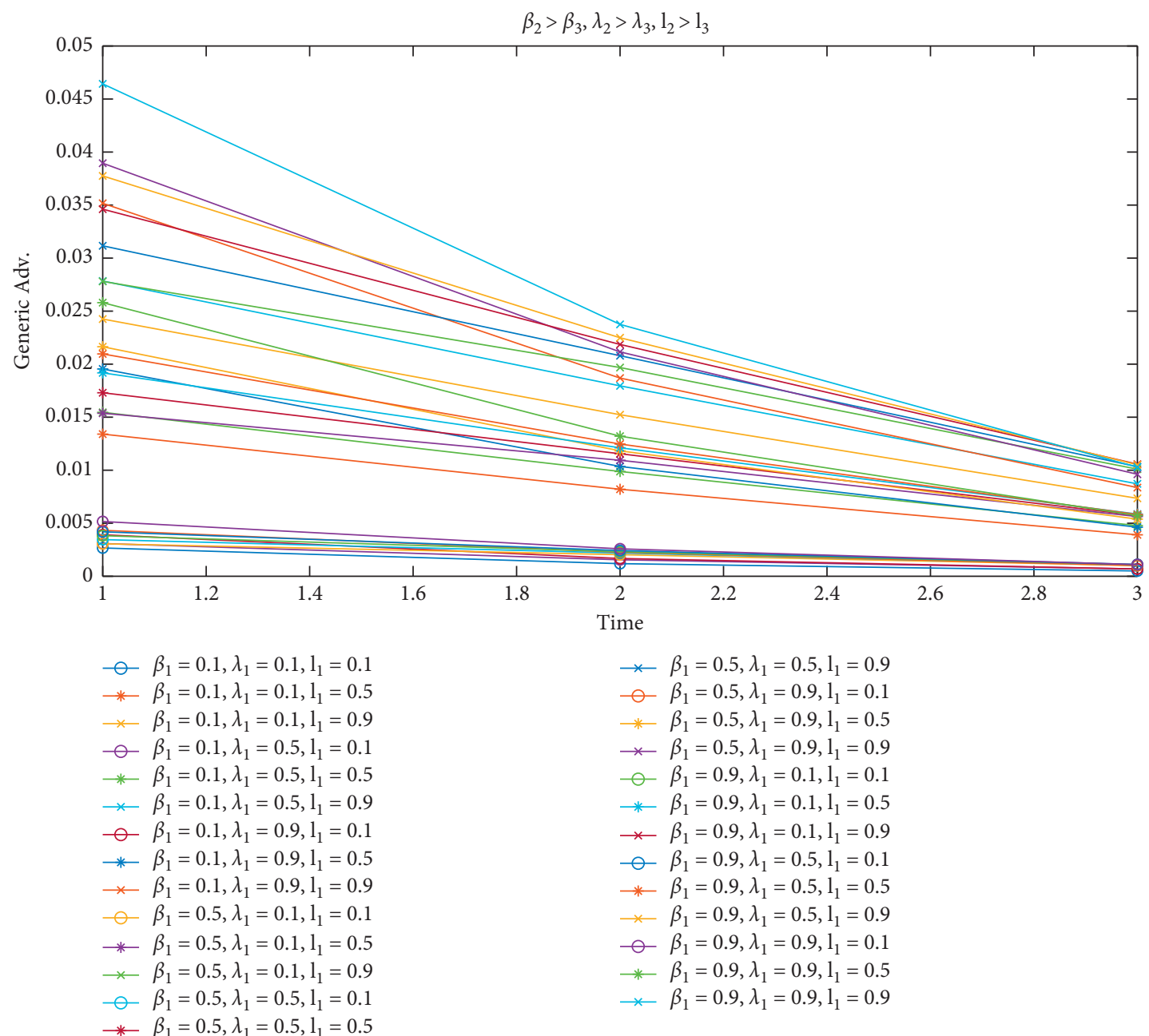

(c)

Figure 3: Continued. 


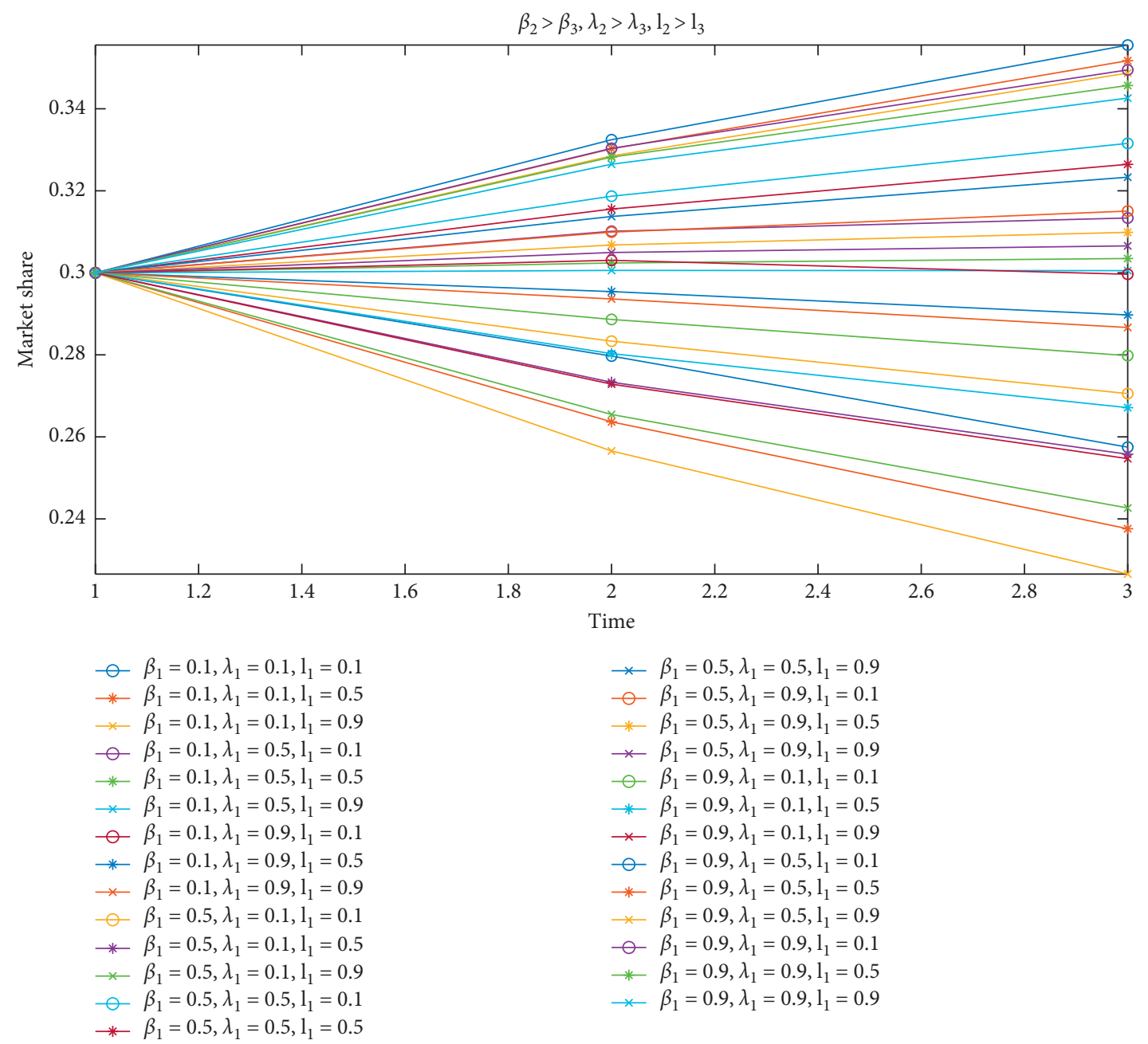

(d)

FIGURE 3: Equilibrium trajectory changes due to advertising effectiveness parameter changes for company 1.

(equation (8)), the solving challenge is related to the term $\left(\partial u_{k} / \partial x_{j}\right)$, because it is necessary to know the equilibrium strategy to calculate it. To solve this problem, Erickson [20] used the concept of conjectural variations and suggested that instead of using $\left(\partial u_{k} / \partial x_{j}\right)$ as a variable, the conjecture of it as a parameter could be used. In this paper, $Z_{u_{i j k}}$ is defined as a conjecture of $\left(\partial u_{k} / \partial x_{j}\right)$ which represents the belief of the $i$-th company about the response of the $k$-th company to change in the state variable of the $j$-th company. Therefore, constraint (8) was converted to $\dot{k}_{i j}=-\left(\partial H_{i} / \partial x_{i}\right)-$ $\sum_{k \neq j}^{n}\left(\partial H_{i} / \partial u_{k}\right) Z_{u_{i j k}}$, and equilibrium strategies can be calculated using the algorithms designed to solve two-point boundary value problems. Also, it is assumed that a company only gives a strategic response to its changes in the state variable, i.e., $Z_{u_{i j k}}=0$ for $j \neq k$. If $Z_{u_{i j k}}=0$ for $j=k$, the dependence of the control variable on the state variable is eliminated, and an open-loop solution is obtained. Finally, in order to determine the trajectory of equilibrium strategies and market share in equilibrium conditions, the following algorithm is used (the flowchart of the solution process is shown in Figure 1):
Step 1. Assign the initial values to $M_{i}(0), i=1,2,3$ and also the final values to $k_{i i}(T)$ and $k_{i j}(T), i, j=1,2, \ldots, N$.

Step 2. Select a beginning value for $a_{i}, d_{i}, g_{i}, i=1,2, \ldots, N$.

Step 3. For $t=1,2, \ldots, T$, calculate the $M_{i}(T), i=1,2, \ldots$, $N$ through forward integration and equation (1).

Step 4. For $t=T, T-1, \ldots, 1$, calculate $k_{i i}(t), i=1,2, \mathrm{~K}, N$ and $k_{i i}(t), i, j=1,2, \mathrm{~K}, N$ through backward integration and equation (8).

Step 5. For $t=1,2, \ldots, T$, calculate $a_{i}(t), d_{i}(t), g_{i}(t)$, $i=1,2, K, N$ through the result of equation (7).

Step 6. If for each $t, a_{i}(t), d_{i}(t)$, or $g_{i}(t), i=1,2, K, N$ is close enough to the value of the previous iteration, stop the algorithm; otherwise, go to Step 3.

In Steps 3 and 4, the fourth-order Runge-Kutta (RK4) method [21] has been used. 


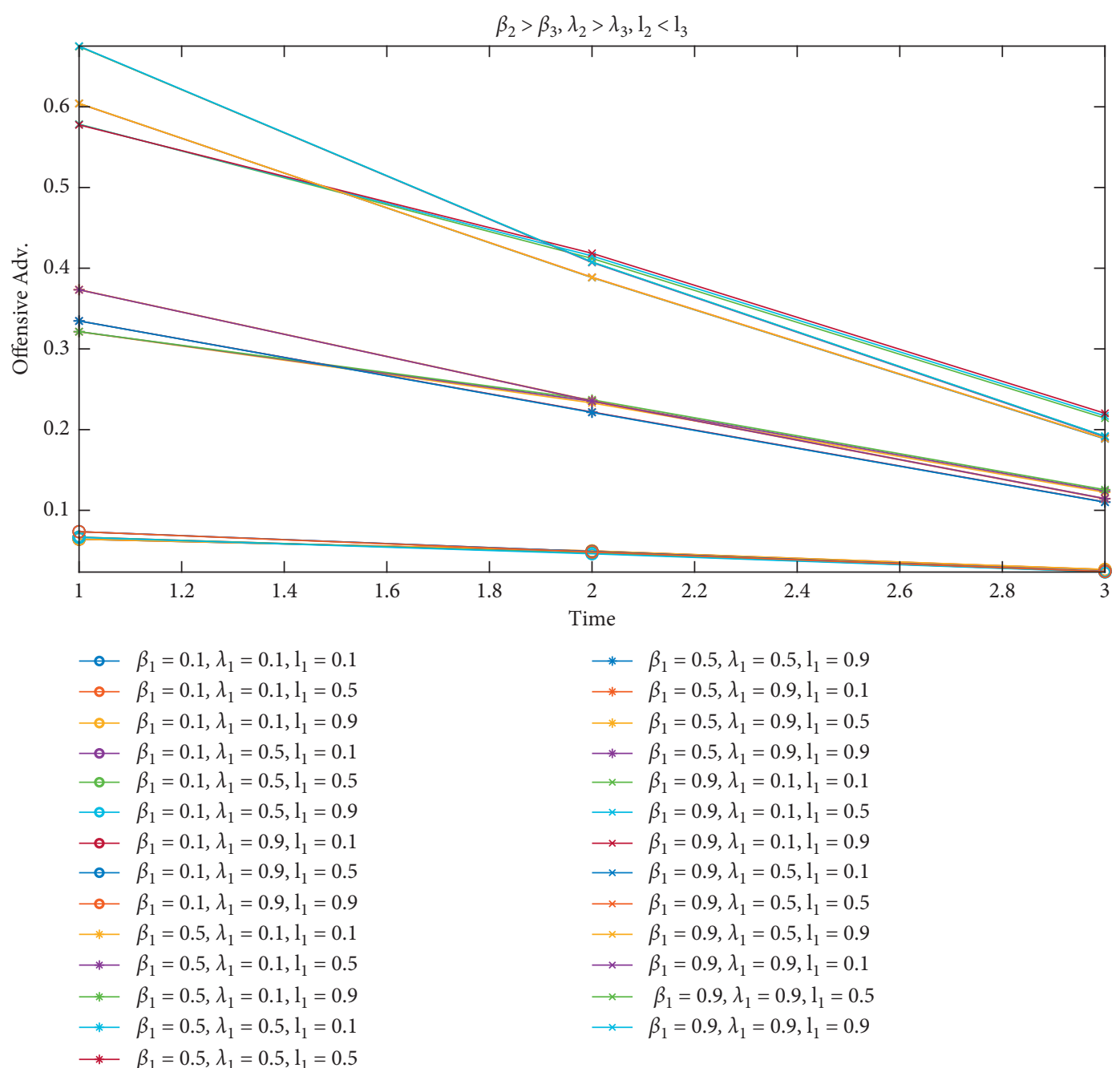

(a)

FIgURE 4: Continued. 


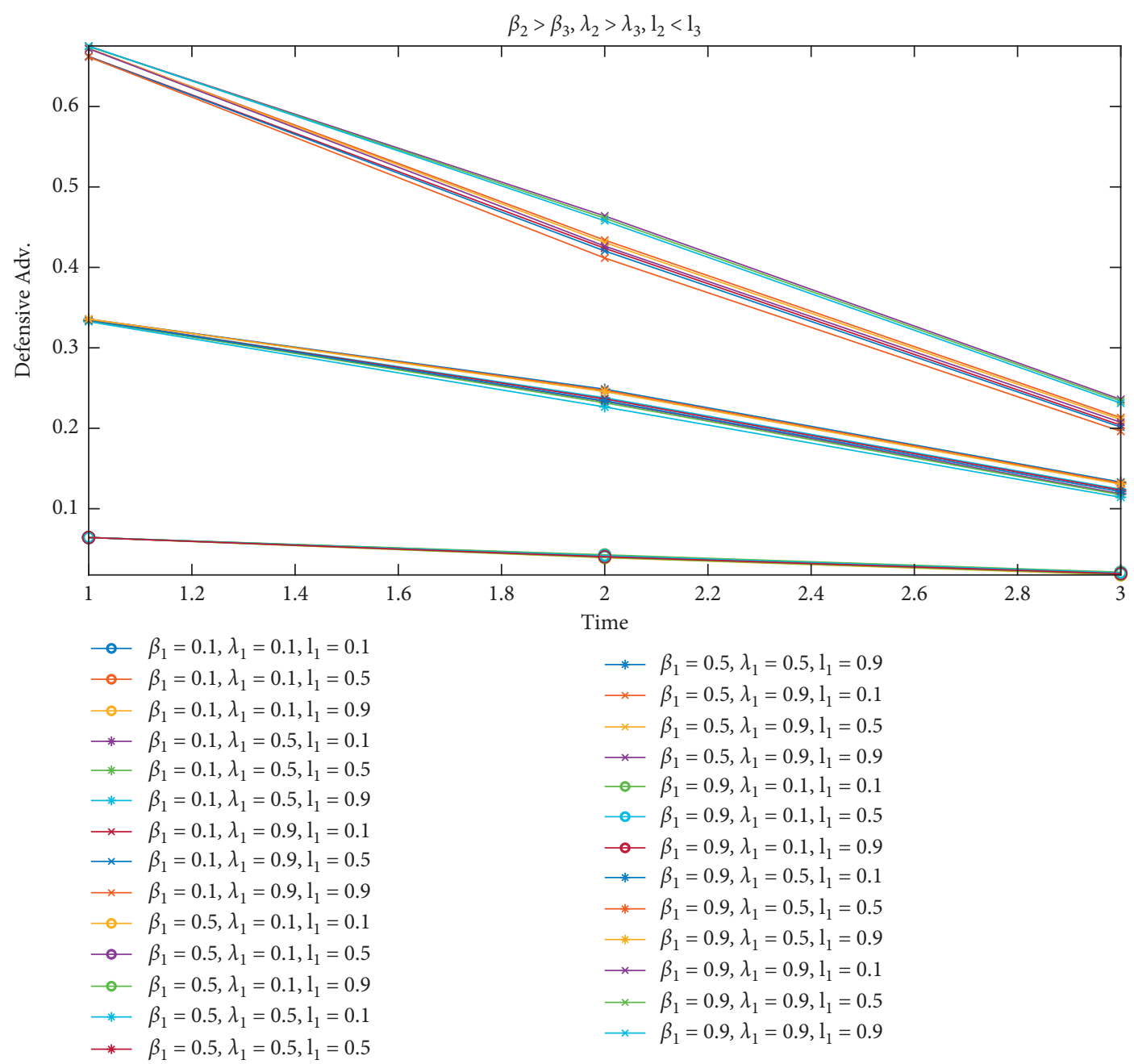

(b)

FIGURE 4: Continued. 


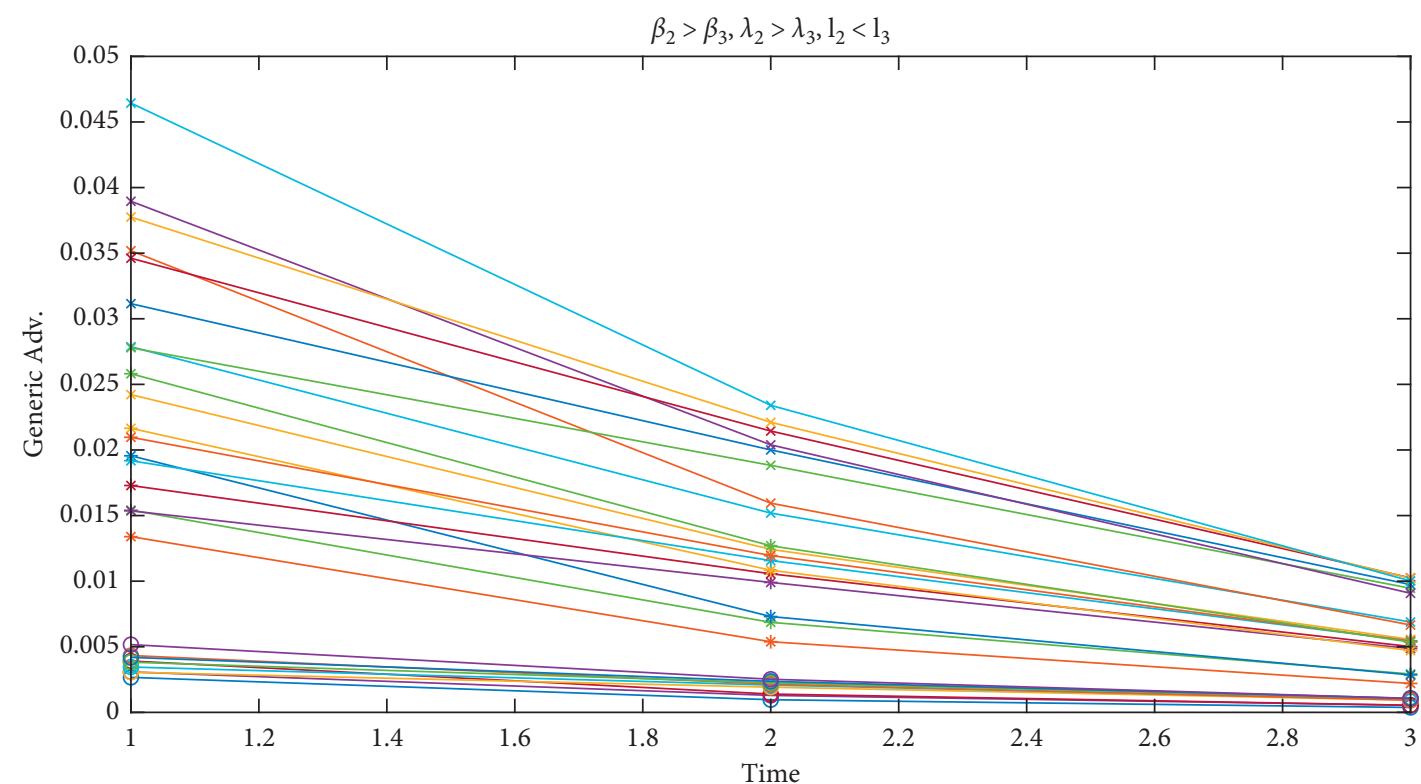

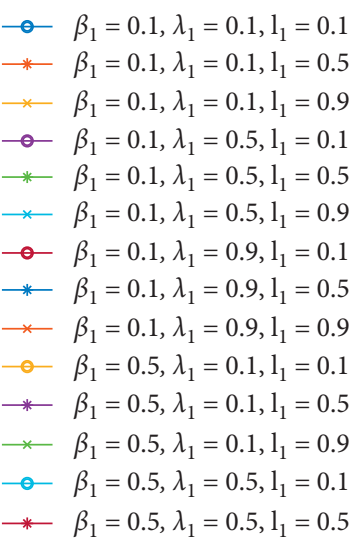

$\times \beta_{1}=0.5, \lambda_{1}=0.5,1_{1}=0.9$

$\multimap \beta_{1}=0.5, \lambda_{1}=0.9,1_{1}=0.1$

$\rightarrow \beta_{1}=0.5, \lambda_{1}=0.9,1_{1}=0.5$

$\rightarrow \beta_{1}=0.5, \lambda_{1}=0.9,1_{1}=0.9$

$\multimap \beta_{1}=0.9, \lambda_{1}=0.1,1_{1}=0.1$

* $\beta_{1}=0.9, \lambda_{1}=0.1,1_{1}=0.5$

$\star \quad \beta_{1}=0.9, \lambda_{1}=0.1,1_{1}=0.9$

$\rightarrow \beta_{1}=0.9, \lambda_{1}=0.5,1_{1}=0.1$

$\rightarrow \beta_{1}=0.9, \lambda_{1}=0.5,1_{1}=0.5$

$\rightarrow \beta_{1}=0.9, \lambda_{1}=0.5,1_{1}=0.9$

$\multimap \beta_{1}=0.9, \lambda_{1}=0.9, l_{1}=0.1$

$\rightarrow \beta_{1}=0.9, \lambda_{1}=0.9,1_{1}=0.5$

$\times \beta_{1}=0.9, \lambda_{1}=0.9,1_{1}=0.9$

(c)

Figure 4: Continued. 


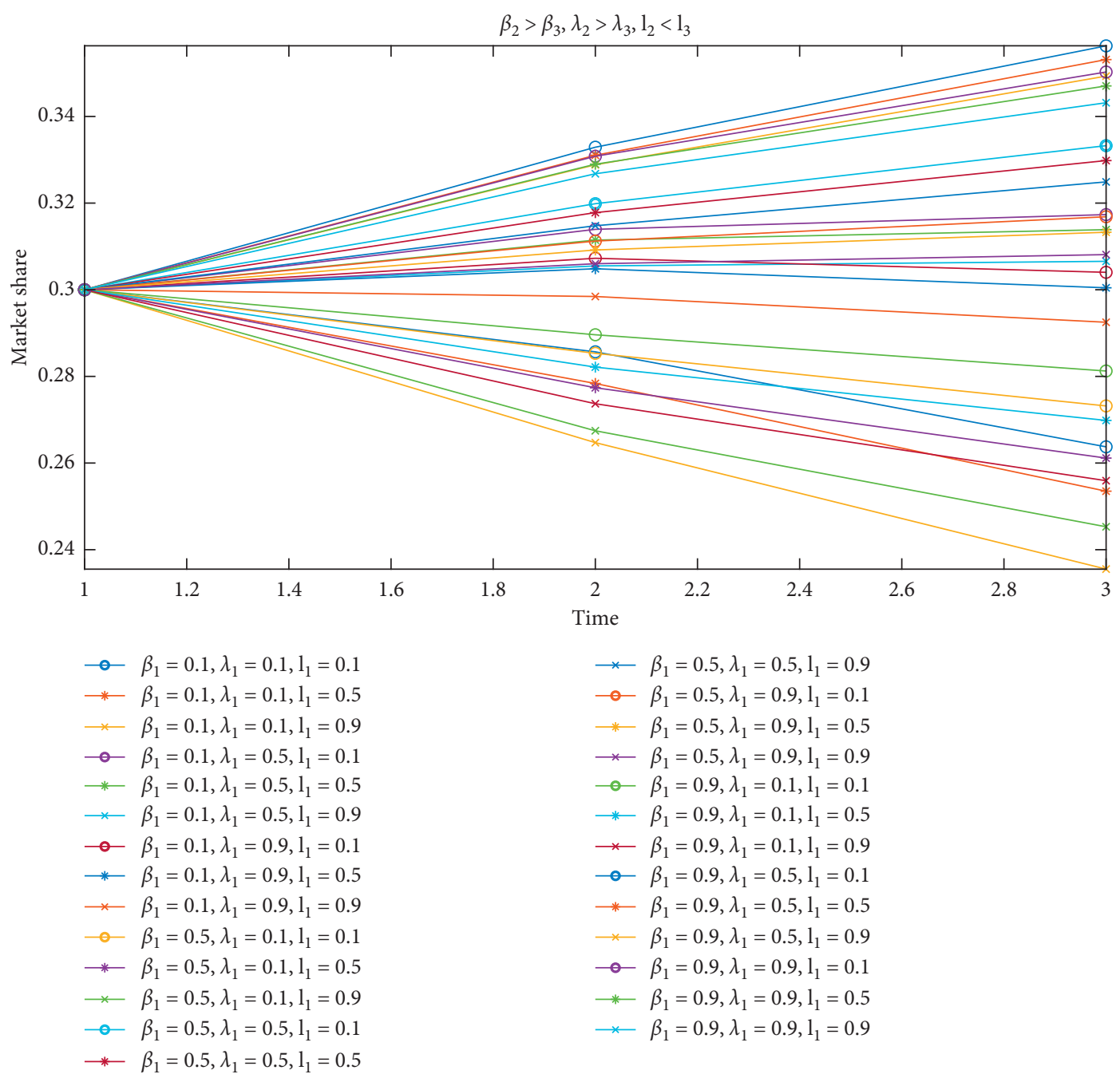

(d)

FIGURE 4: Equilibrium trajectory changes due to advertising effectiveness parameter changes for Scenario 2.

\section{Numerical Illustration in a Triopoly Market}

This section presents equilibrium advertising strategies and equilibrium market shares for a hypothetical example in a triopoly market. Suppose that three companies $(N=3)$ in the triopoly market, with the potential $V$, intend to determine their offensive, defensive, and generic advertising strategies to optimize their profits. In the presented numerical example, a realistic assumption has been considered whereby at the end of the time horizon, the market share variable (the state variable) can take any value. Therefore, $M_{i}(T)$ is a free variable and its shadow price at the end of the period $\left(k_{i j}(T)\right)$ must be zero. Figure 2 shows the equilibrium trajectories of offensive, defensive, and generic strategies as well as the market share for company 1 using the numerical process presented in Section 4 with the same initial market share values for the three companies $\left(M_{i}(0)=0.3\right.$, for $\left.i=1,2,3\right)$ and with the hypothetical values for the problem parameters $\left(\pi_{i}=0.3, C_{a}=C_{d}=\right.$ $\left.C_{g}=0.2, \beta_{i}=0.4, \lambda_{i}=0.3, l_{i}=0.2, \forall i\right)$. These figures show the equilibrium values at any given time for each of the three companies. In the feedback solution approach, the changes to the optimal advertising strategies depend on the state of the system (the market share of the companies). Therefore, according to the explanation given in the second paragraph of Section 4 , these conditions are described as $Z_{a_{i j j}}=Z_{d_{i j j}}=Z_{g_{i j j}} \neq 0$.

As shown in Figure 2, in equilibrium conditions, as $Z_{U_{i j j}}$ increases, the offensive and defensive advertising strategies are increased, whereas the generic advertising strategy and the market share are decreased. Also, by decreasing the value of $Z_{U_{i j j}}$, the offensive and defensive advertising strategies are decreased, and the generic advertising strategy and the market share are increased. Intuitively, it can be said that considering the constraints $\beta_{i}>\lambda_{i}>l_{i}, i=1,2,3$, in equilibrium conditions, the belief about the positive response of competitors to their own market share changes leads to an increase in the offensive and defensive strategy, as well as the equilibrium market share; while it results in the reduction in the generic strategy. Conversely, the belief in the negative response of competitors to changes in their 


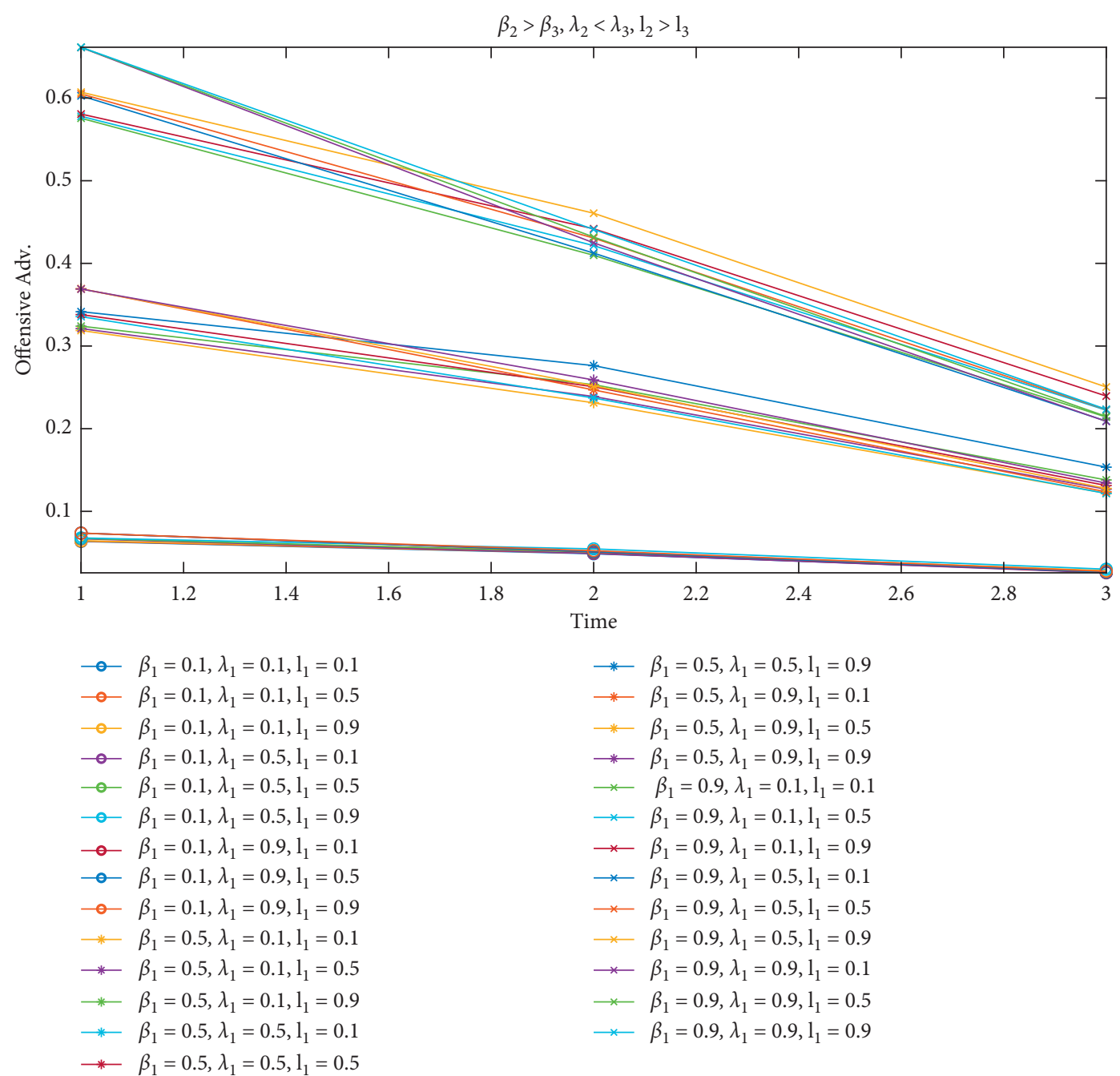

(a)

Figure 5: Continued. 


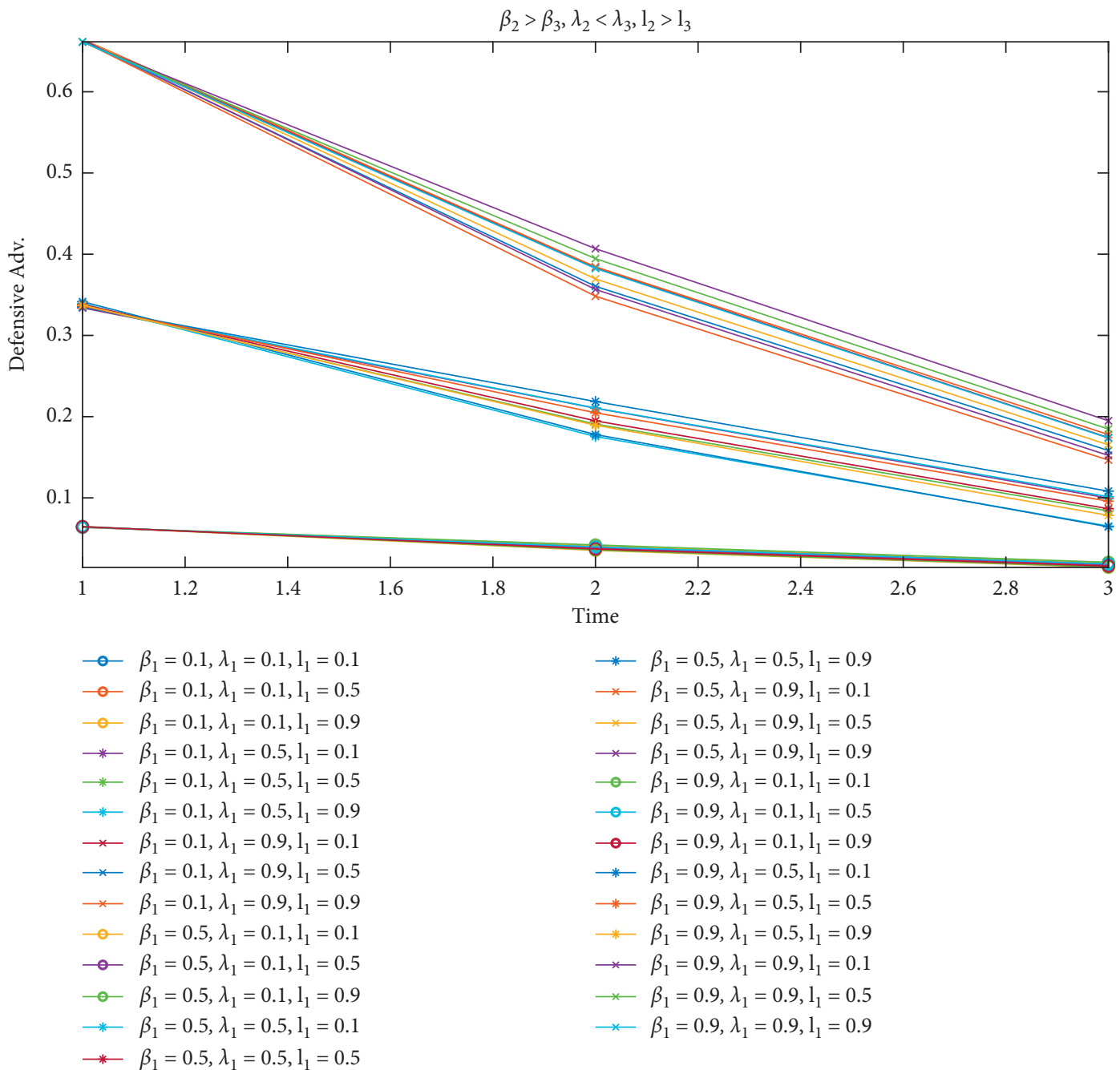

(b)

Figure 5: Continued. 


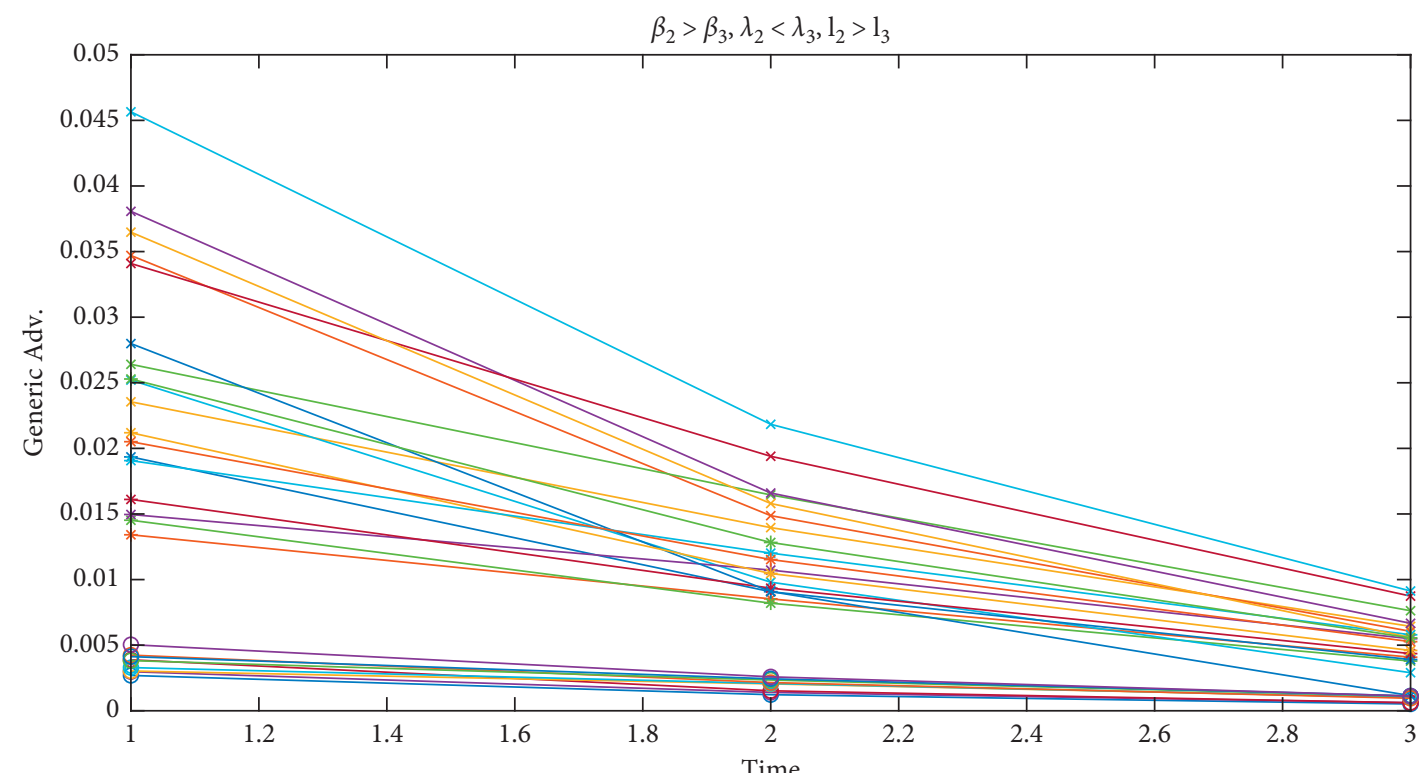

$\multimap \beta_{1}=0.1, \lambda_{1}=0.1,1_{1}=0.1$

* $\beta_{1}=0.1, \lambda_{1}=0.1,1_{1}=0.5$

$\therefore \beta_{1}=0.1, \lambda_{1}=0.1,1_{1}=0.9$

$\multimap \beta_{1}=0.1, \lambda_{1}=0.5,1_{1}=0.1$

$\rightarrow \beta_{1}=0.1, \lambda_{1}=0.5,1_{1}=0.5$

$\rightarrow \beta_{1}=0.1, \lambda_{1}=0.5,1_{1}=0.9$

$\therefore \beta_{1}=0.1, \lambda_{1}=0.9,1_{1}=0.1$

* $\quad \beta_{1}=0.1, \lambda_{1}=0.9,1_{1}=0.5$

$\star \quad \beta_{1}=0.1, \lambda_{1}=0.9,1_{1}=0.9$

$\multimap \beta_{1}=0.5, \lambda_{1}=0.1,1_{1}=0.1$

* $\beta_{1}=0.5, \lambda_{1}=0.1,1_{1}=0.5$

$\star \beta_{1}=0.5, \lambda_{1}=0.1, l_{1}=0.9$

$\multimap \beta_{1}=0.5, \lambda_{1}=0.5,1_{1}=0.1$

$\rightarrow \beta_{1}=0.5, \lambda_{1}=0.5,1_{1}=0.5$ $\rightarrow \beta_{1}=0.5, \lambda_{1}=0.5,1_{1}=0.9$

$\multimap \beta_{1}=0.5, \lambda_{1}=0.9,1_{1}=0.1$

* $\beta_{1}=0.5, \lambda_{1}=0.9,1_{1}=0.5$

$\star \beta_{1}=0.5, \lambda_{1}=0.9,1_{1}=0.9$

$\multimap \beta_{1}=0.9, \lambda_{1}=0.1,1_{1}=0.1$

$\rightarrow \beta_{1}=0.9, \lambda_{1}=0.1,1_{1}=0.5$

$\star \quad \beta_{1}=0.9, \lambda_{1}=0.1,1_{1}=0.9$

$\rightarrow \beta_{1}=0.9, \lambda_{1}=0.5,1_{1}=0.1$

$\rightarrow \beta_{1}=0.9, \lambda_{1}=0.5,1_{1}=0.5$

$\leftarrow \beta_{1}=0.9, \lambda_{1}=0.5,1_{1}=0.9$

$\multimap \beta_{1}=0.9, \lambda_{1}=0.9,1_{1}=0.1$

$\rightarrow \beta_{1}=0.9, \lambda_{1}=0.9,1_{1}=0.5$

$\longrightarrow \quad \beta_{1}=0.9, \lambda_{1}=0.9,1_{1}=0.9$

(c)

FIgURE 5: Continued. 


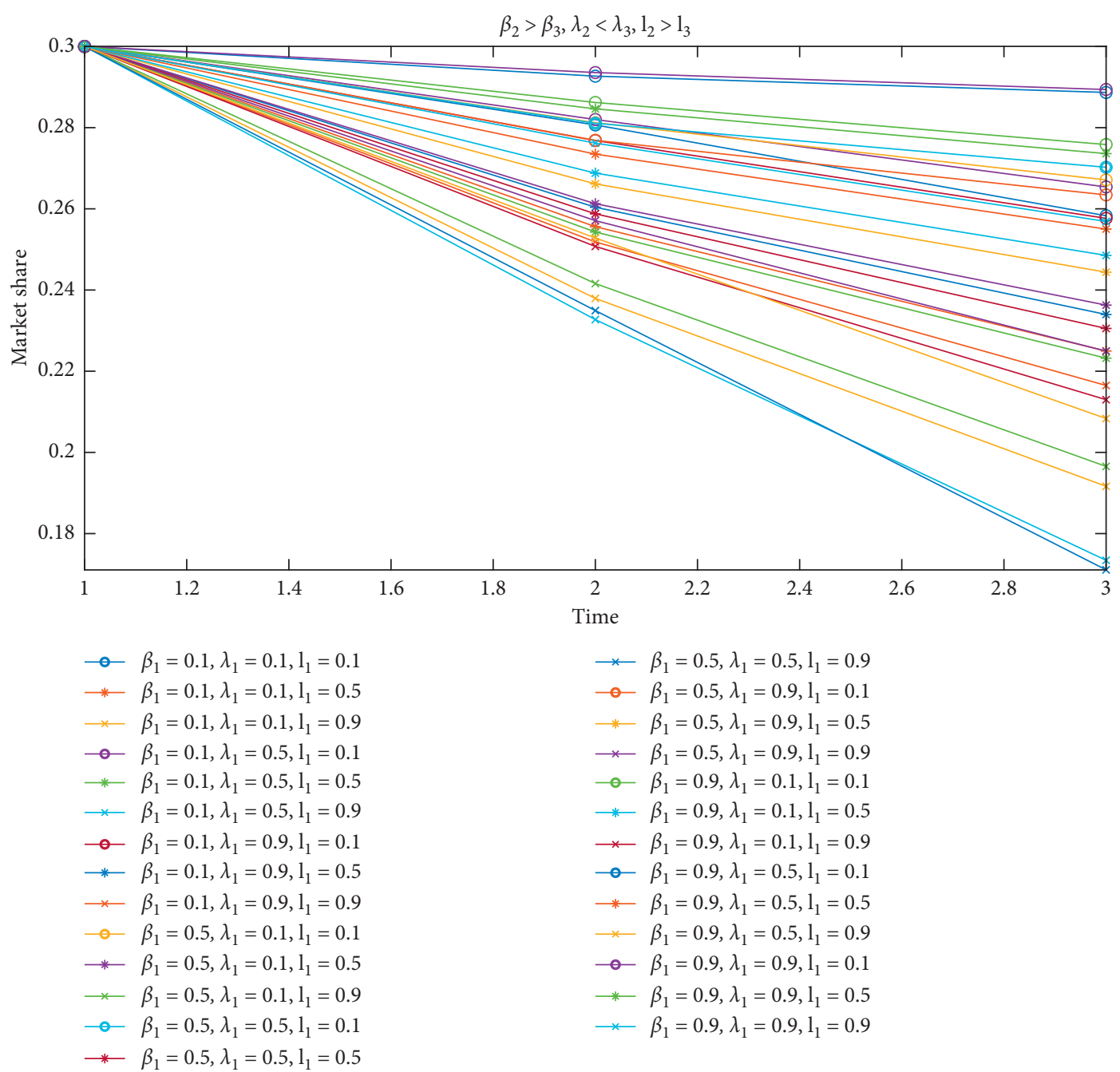

(d)

FIGURE 5: Equilibrium trajectory changes due to advertising effectiveness parameter changes for Scenario 3.

market share leads to a reduction in the offensive strategy, defensive strategy, and equilibrium market share and to an increase in the generic strategy.

5.1. Asymmetric Condition. In this section, the changes in equilibrium strategies and market share with respect to changes in the advertising effectiveness parameters $\left(\beta_{i} ، \lambda_{i} l_{i}\right)$ are examined. These estimations are performed in open-loop conditions, taking into account the constraint $Z_{U_{i j j}}=0$. Finally, simultaneous variations of the variable $Z_{U_{i j j}}$ and effectiveness parameters are examined.

5.1.1. The Effect of Advertising Effective Parameters. Experiments with three levels of parameters (0.1, 0.5, and $0.9)$ are designed to test the effects of variations in the offensive, defensive, and generic advertising effectiveness parameters on equilibrium market strategies and market share. The other parameters are assumed to be identical for the three companies. The effect analysis of the advertising effectiveness parameters is examined under the following four scenarios. Other states (such as scenarios where $\beta_{3}>\beta_{2}$ ) are eliminated due to symmetry in other parameters and the creation of similar situations:

$$
\begin{aligned}
& \text {.Scenario 1: } \beta_{2}>\beta_{3}, \lambda_{2}>\lambda_{3}, l_{2}>l_{3} \text {, } \\
& \text {.Scenario 2: } \beta_{2}>\beta_{3}, \lambda_{2}>\lambda_{3}, l_{2}<l_{3} \text {, } \\
& \text {.Scenario 3: } \beta_{2}>\beta_{3}, \lambda_{2}<\lambda_{3}, l_{2}>l_{3} \text {, } \\
& \text {.Scenario 4: } \beta_{2}>\beta_{3}, \lambda_{2}<\lambda_{3}, l_{2}<l_{3} \text {. }
\end{aligned}
$$

Figure 3 shows the details of the first company equilibrium paths for different advertising effectiveness parameter values of scenario 1 . The other scenarios' equilibrium trajectories are presented in Figures 4-6and Table 4 (Figures 4-6 show the equilibrium trajectory changes due to the advertising effectiveness parameter changes for scenario 2, scenario 3, and scenario 4, respectively). By comparing four scenarios, changes in the advertising effectiveness parameters lead to similar behavior in the equilibrium trajectories, as shown in Table 4. At each row in Table 4, positive or negative changes to the 


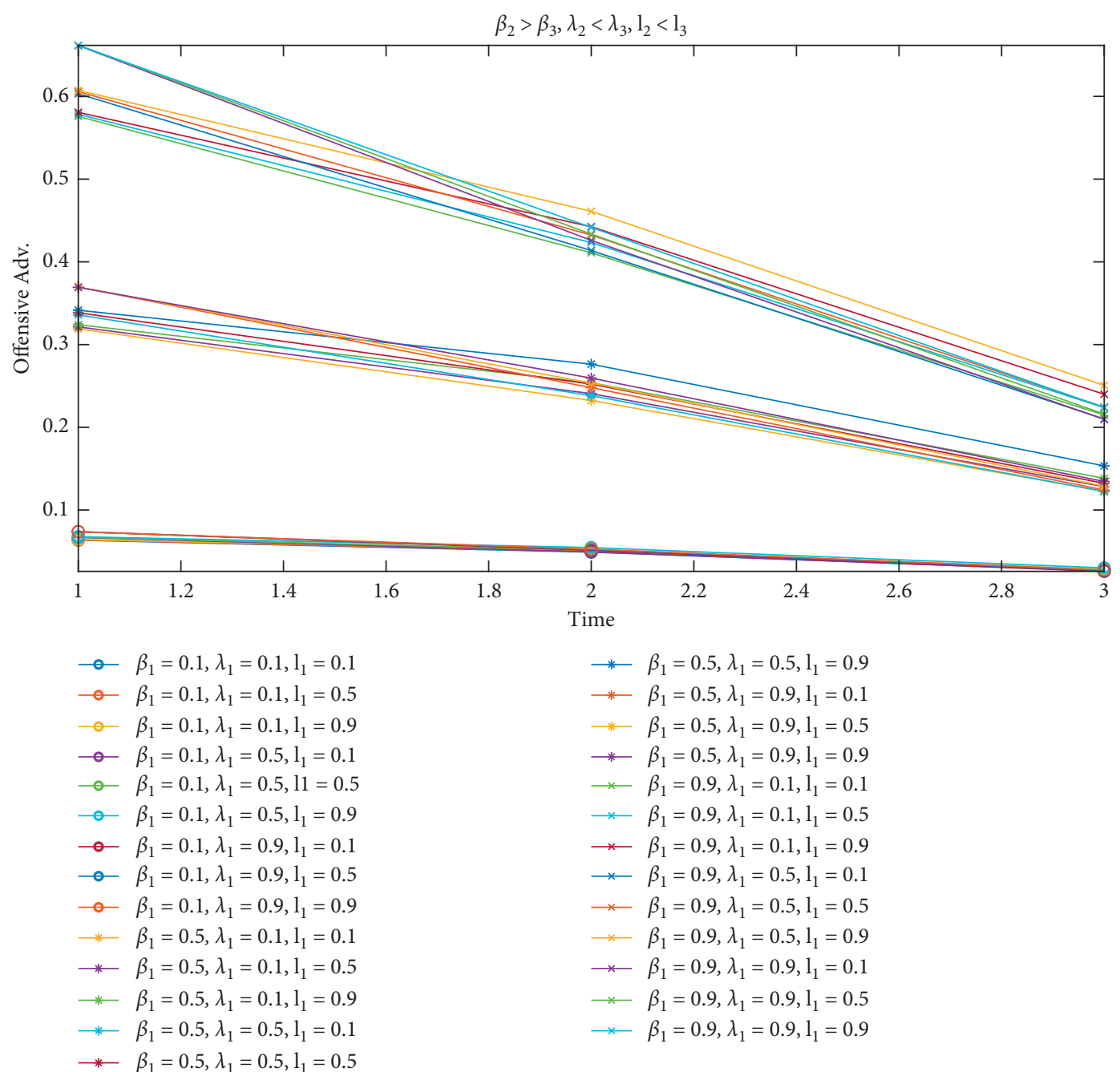

(a)

Figure 6: Continued. 


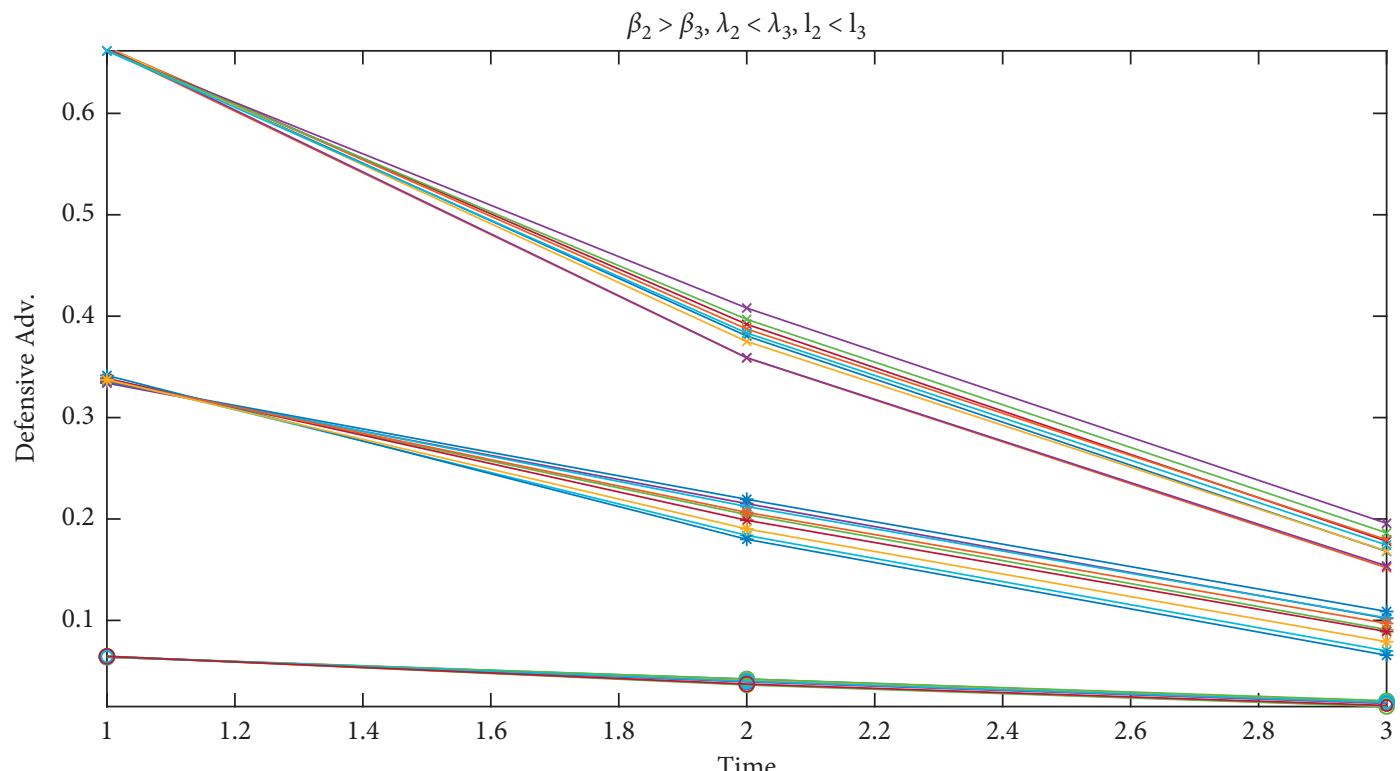

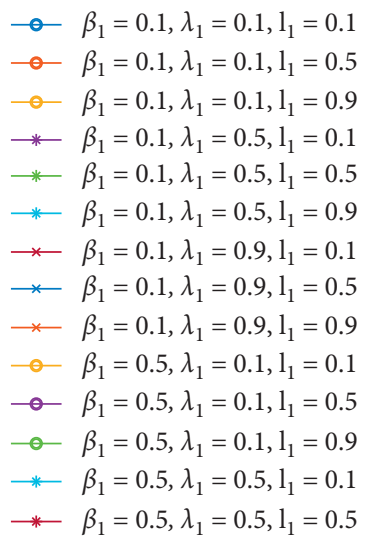

$\rightarrow \beta_{1}=0.5, \lambda_{1}=0.5,1_{1}=0.9$

$\because \beta_{1}=0.5, \lambda_{1}=0.9,1_{1}=0.1$

$\leftarrow \beta_{1}=0.5, \lambda_{1}=0.9,1_{1}=0.5$

$* \beta_{1}=0.5, \lambda_{1}=0.9,1_{1}=0.9$

$\rightarrow \beta_{1}=0.9, \lambda_{1}=0.1,1_{1}=0.1$

$\rightarrow \beta_{1}=0.9, \lambda_{1}=0.1,1_{1}=0.5$

$\rightarrow \beta_{1}=0.9, \lambda_{1}=0.1,1_{1}=0.9$

$\rightarrow \beta_{1}=0.9, \lambda_{1}=0.5,1_{1}=0.1$

$\rightarrow \beta_{1}=0.9, \lambda_{1}=0.5,1_{1}=0.5$

* $\beta_{1}=0.9, \lambda_{1}=0.5,1_{1}=0.9$

$\star \beta_{1}=0.9, \lambda_{1}=0.9,1_{1}=0.1$

$\times \beta_{1}=0.9, \lambda_{1}=0.9,1_{1}=0.5$

$\star \beta_{1}=0.9, \lambda_{1}=0.9,1_{1}=0.9$

(b)

Figure 6: Continued. 


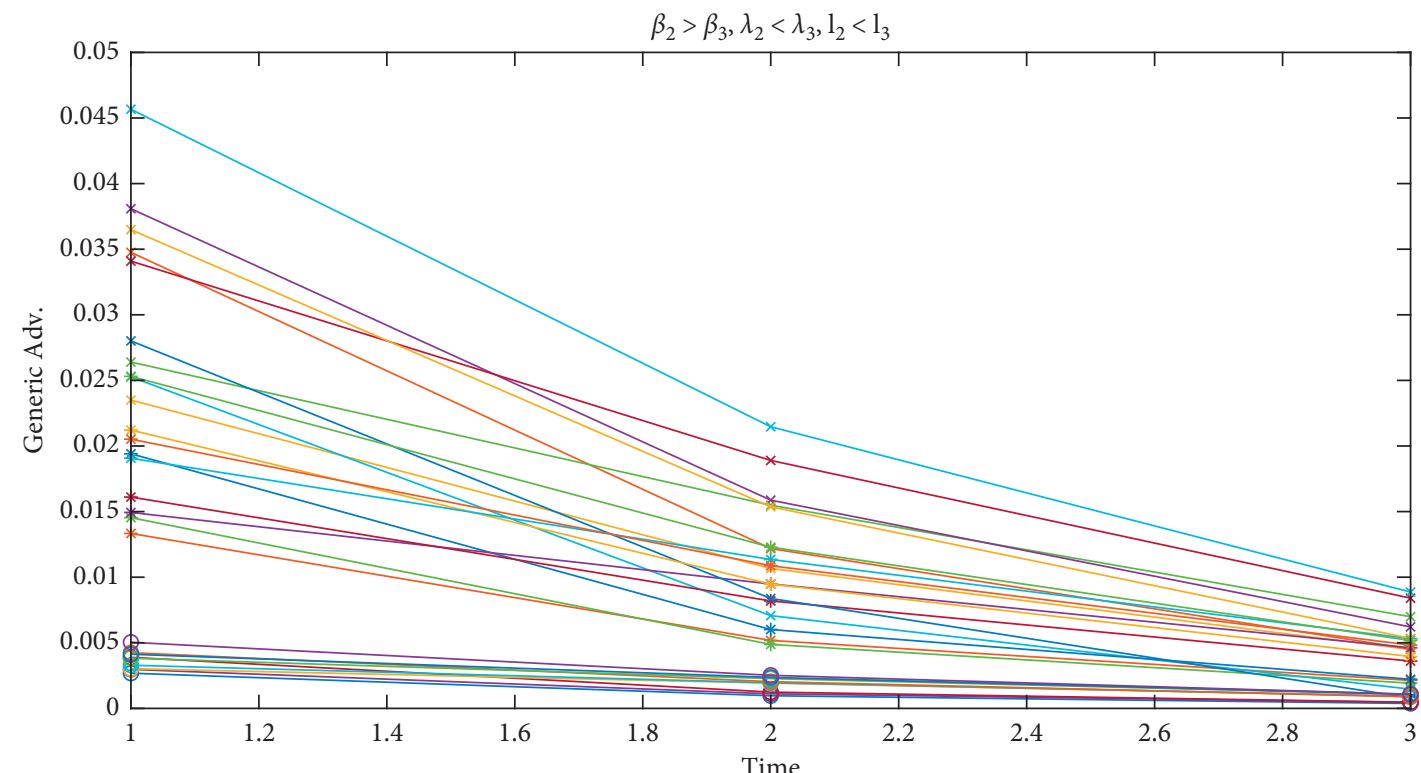

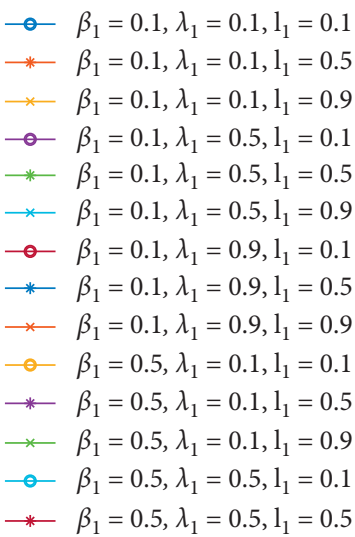

$\star \beta_{1}=0.5, \lambda_{1}=0.5,1_{1}=0.9$

$\therefore \beta_{1}=0.5, \lambda_{1}=0.9,1_{1}=0.1$

$\rightarrow \beta_{1}=0.5, \lambda_{1}=0.9,1_{1}=0.5$

$\rightarrow \quad \beta_{1}=0.5, \lambda_{1}=0.9,1_{1}=0.9$

$\rightarrow \beta_{1}=0.9, \lambda_{1}=0.1,1_{1}=0.1$

$\rightarrow \beta_{1}=0.9, \lambda_{1}=0.1,1_{1}=0.5$

$\times \beta_{1}=0.9, \lambda_{1}=0.1,1_{1}=0.9$

$\rightarrow \beta_{1}=0.9, \lambda_{1}=0.5,1_{1}=0.1$

$\rightarrow \quad \beta_{1}=0.9, \lambda_{1}=0.5,1_{1}=0.5$

$\lessdot \beta_{1}=0.9, \lambda_{1}=0.5,1_{1}=0.9$

$\multimap \beta_{1}=0.9, \lambda_{1}=0.9,1_{1}=0.1$

$\rightarrow \beta_{1}=0.9, \lambda_{1}=0.9,1_{1}=0.5$

$\longrightarrow \beta_{1}=0.9, \lambda_{1}=0.9,1_{1}=0.9$

(c)

Figure 6: Continued. 


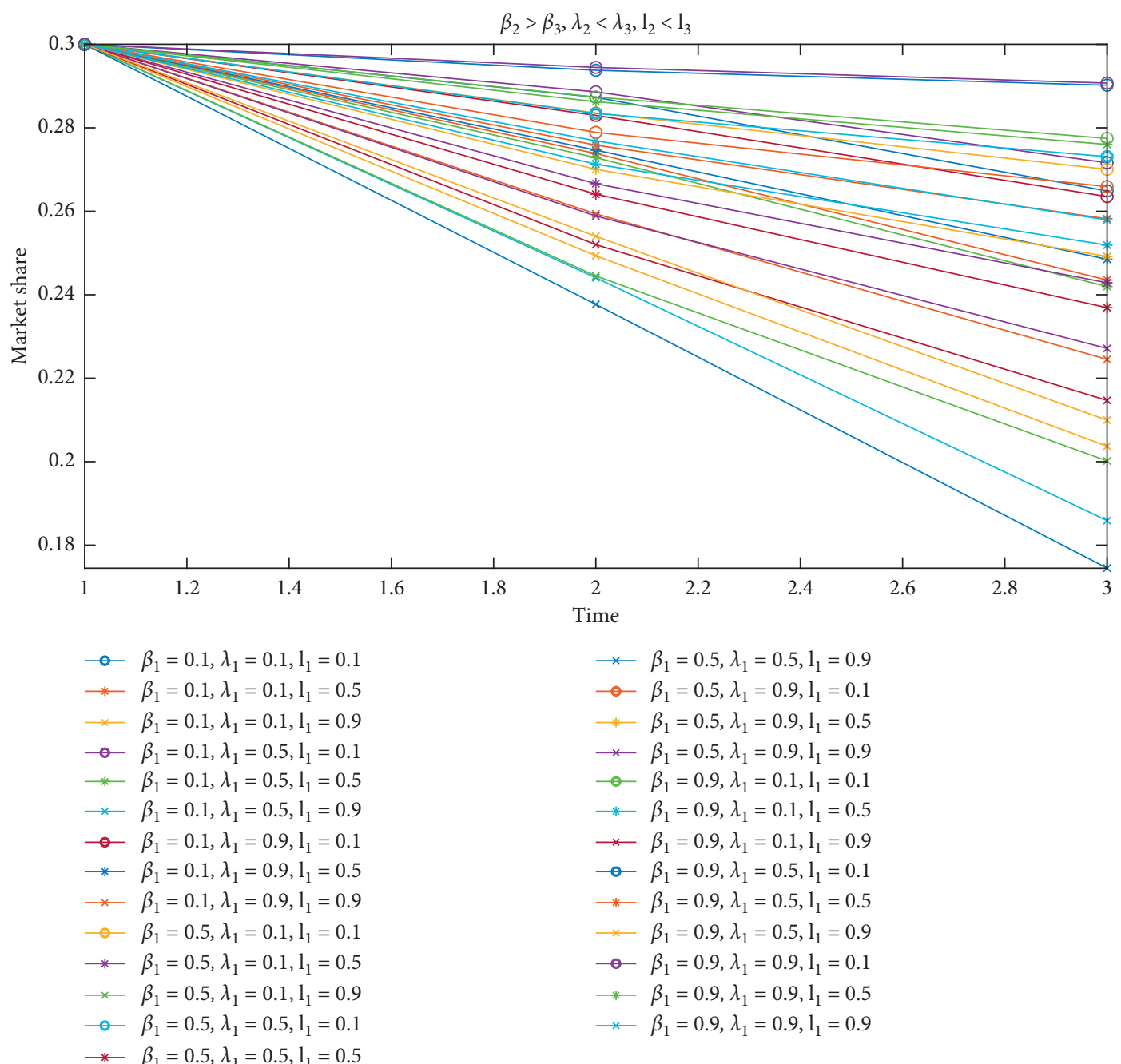

(d)

FIgURE 6: Equilibrium trajectory changes due to advertising effectiveness parameter changes for Scenario 4.

first firm's advertising strategies were obtained, assuming the other two parameters were identical.

5.1.2. The Effect of Marginal Profit. In this section, the effect of marginal profit changes on equilibrium trajectories is examined. Because of the large number of problem parameters, the variations of $\pi_{i}$ by assuming equality of the other parameters are investigated. The values of the other parameters are the same as those given in Section 5. The equilibrium trajectory changes are evaluated based on $\pi_{i}, i=$ $1,2,3$ at three levels of $0.1,0.3$, and 0.5 . Figure 7 shows the equilibrium trajectory changes of the first company. As can be seen, increasing the marginal profit $\pi_{i}$ has led to an increase in the equilibrium advertising strategies.

5.1.3. The Effect of Initial Market Share. Advertising differential games begin with the assumption of an initial market share for the players and become steady over time. In this section, the behavior of equilibrium trajectories with respect to changes in the initial market share is examined. The evaluating process is similar to the previous section, with three levels of $0.15,0.25$, and 0.35 for initial market shares. Figure 8 shows these results. As can be seen, by increasing competitor market share, the level of offensive advertising 


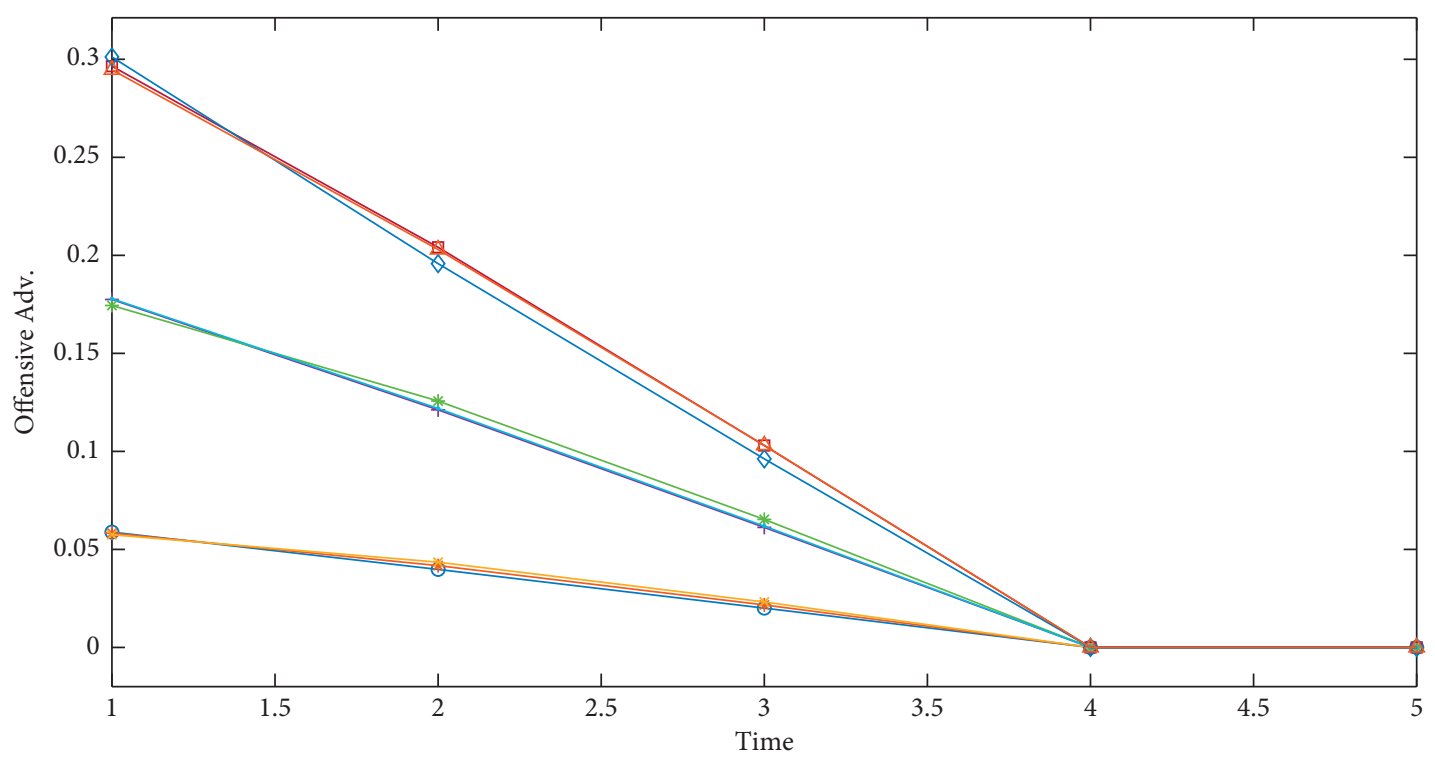
$\ominus \pi_{1}=0.1, \pi_{2}=0.1, \pi_{3}=0.1$
* $\pi_{1}=0.1, \pi_{2}=0.3, \pi_{3}=0.3$
$\rightarrow \pi_{1}=0.1, \pi_{2}=0.5, \pi_{3}=0.5$
$-\pi_{1}=0.3, \pi_{2}=0.1, \pi_{3}=0.3$
$\square \pi_{1}=0.3, \pi_{2}=0.5, \pi_{3}=0.1$
$\square \quad \pi_{1}=0.5, \pi_{2}=0.1, \pi_{3}=0.5$
$\smile \quad \pi_{1}=0.5, \pi_{2}=0.3, \pi_{3}=0.1$
$\triangle \quad \pi_{1}=0.5, \pi_{2}=0.5, \pi_{3}=0.3$

$\rightarrow-\pi_{1}=0.3, \pi_{2}=0.3, \pi_{3}=0.5$

(a)

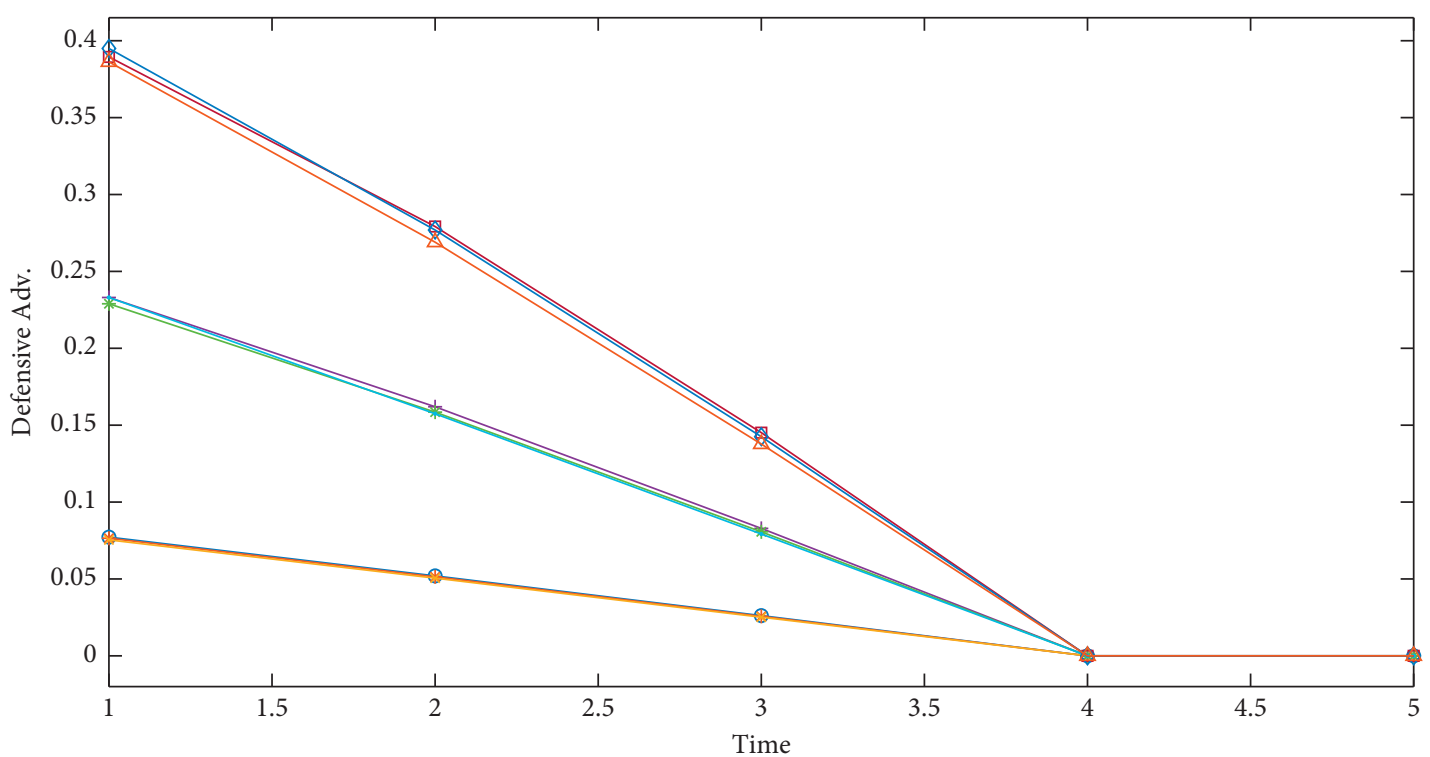

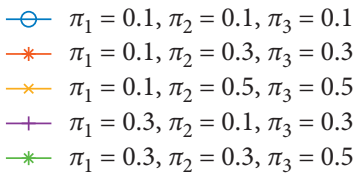

$\longrightarrow \pi_{1}=0.3, \pi_{2}=0.5, \pi_{3}=0.1$

$\square-\pi_{1}=0.5, \pi_{2}=0.1, \pi_{3}=0.5$

$\neg \pi_{1}=0.5, \pi_{2}=0.3, \pi_{3}=0.1$

$\triangle \pi_{1}=0.5, \pi_{2}=0.5, \pi_{3}=0.3$

(b)

Figure 7: Continued. 


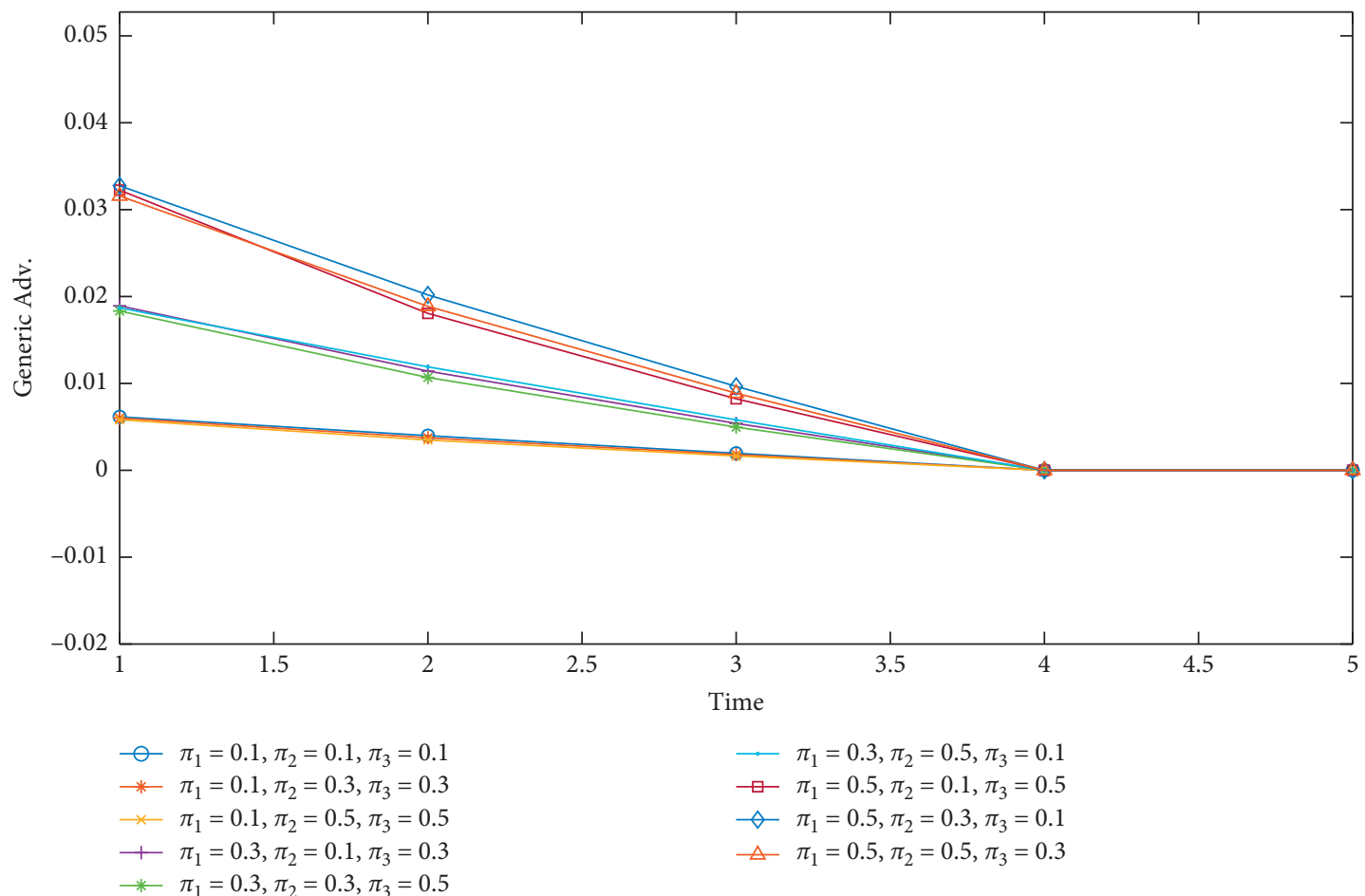

(c)

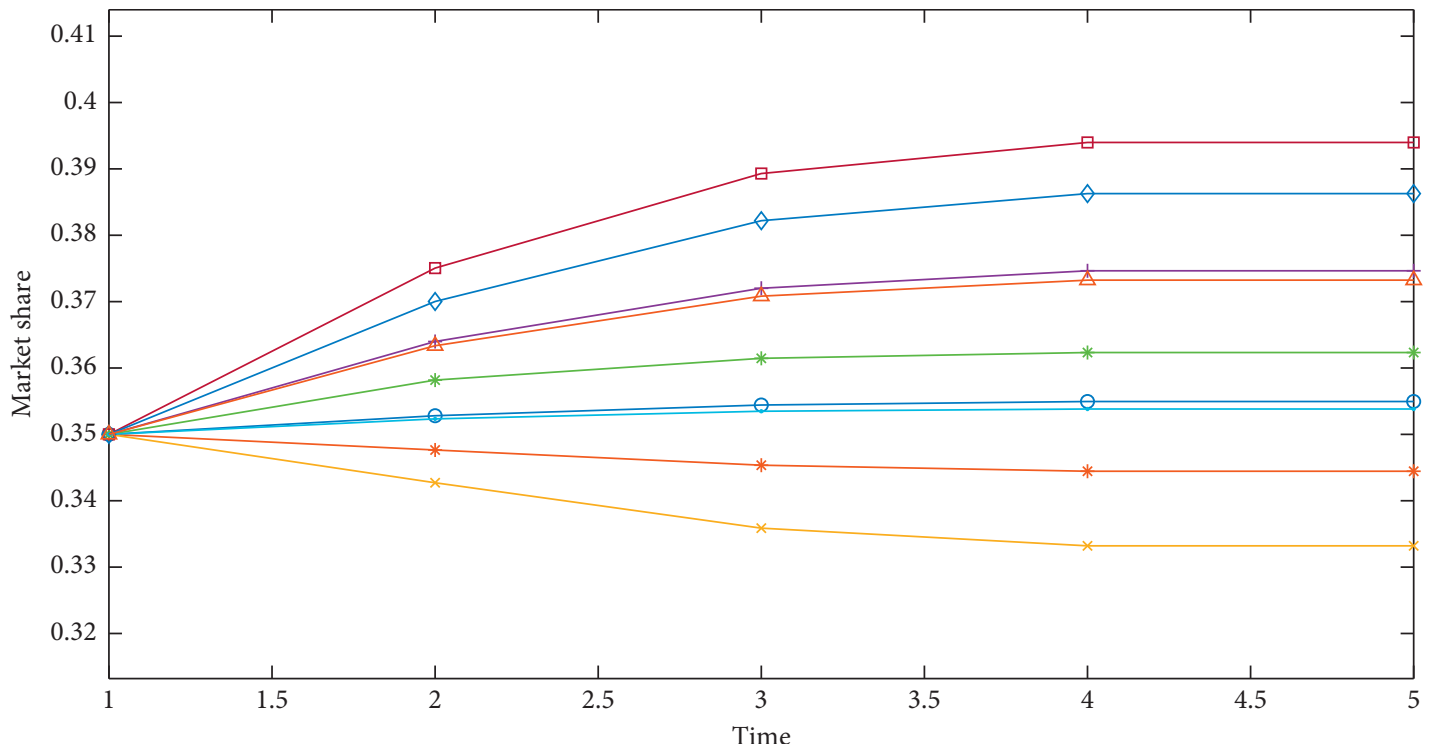

$-\pi_{1}=0.1, \pi_{2}=0.1, \pi_{3}=0.1$
$-* \pi_{1}=0.1, \pi_{2}=0.3, \pi_{3}=0.3$
$-\leftarrow \pi_{1}=0.1, \pi_{2}=0.5, \pi_{3}=0.5$
$+\quad \pi_{1}=0.3, \pi_{2}=0.1, \pi_{3}=0.3$
$\rightarrow-\pi_{1}=0.3, \pi_{2}=0.3, \pi_{3}=0.5$

$\longrightarrow \pi_{1}=0.3, \pi_{2}=0.5, \pi_{3}=0.1$

$\square-\pi_{1}=0.5, \pi_{2}=0.1, \pi_{3}=0.5$

$\diamond \pi_{1}=0.5, \pi_{2}=0.3, \pi_{3}=0.1$

$\triangle \pi_{1}=0.5, \pi_{2}=0.5, \pi_{3}=0.3$

(d)

FIGURE 7: Equilibrium trajectory changes due to marginal profit changes for company 1. 


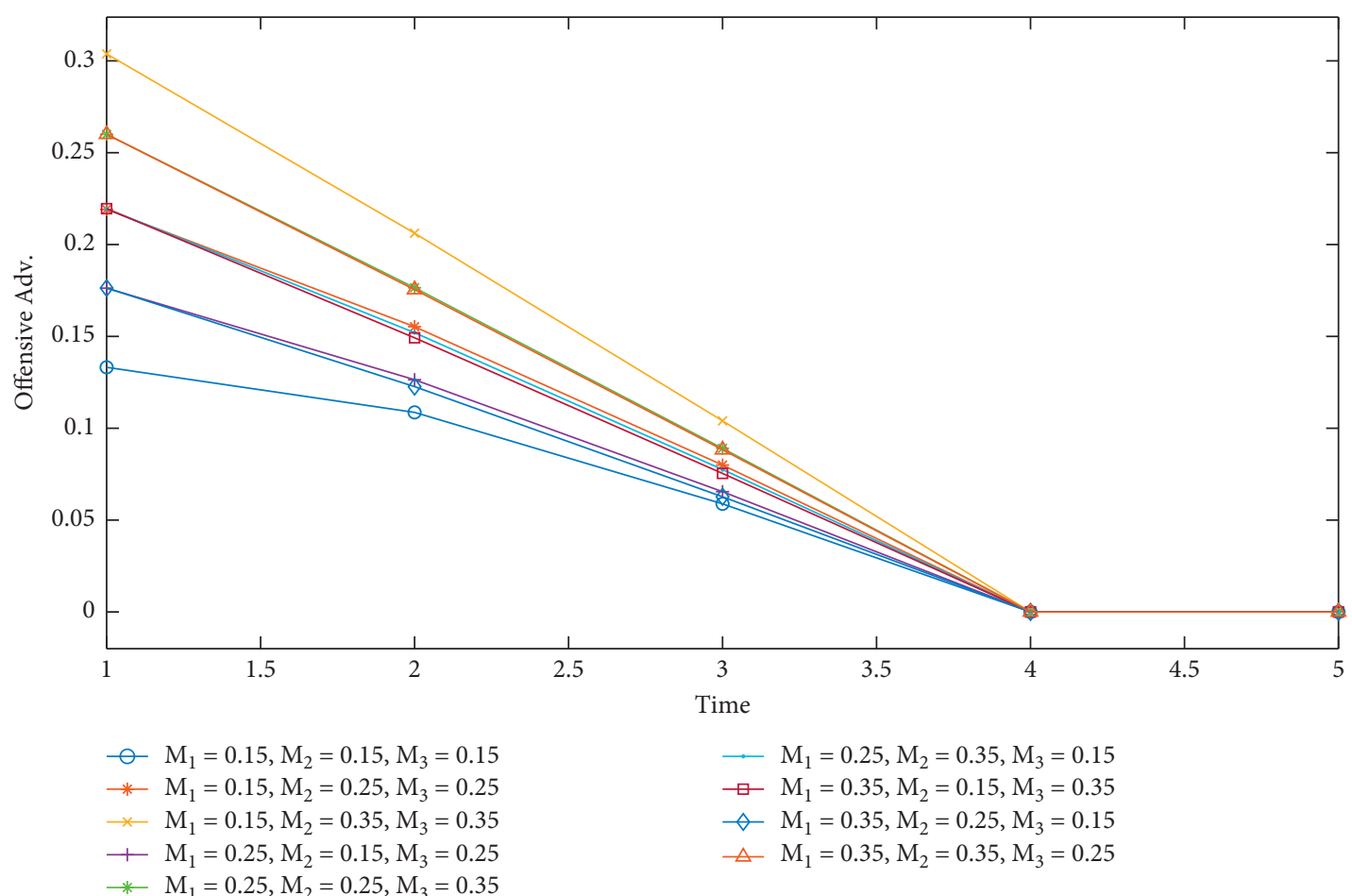

(a)

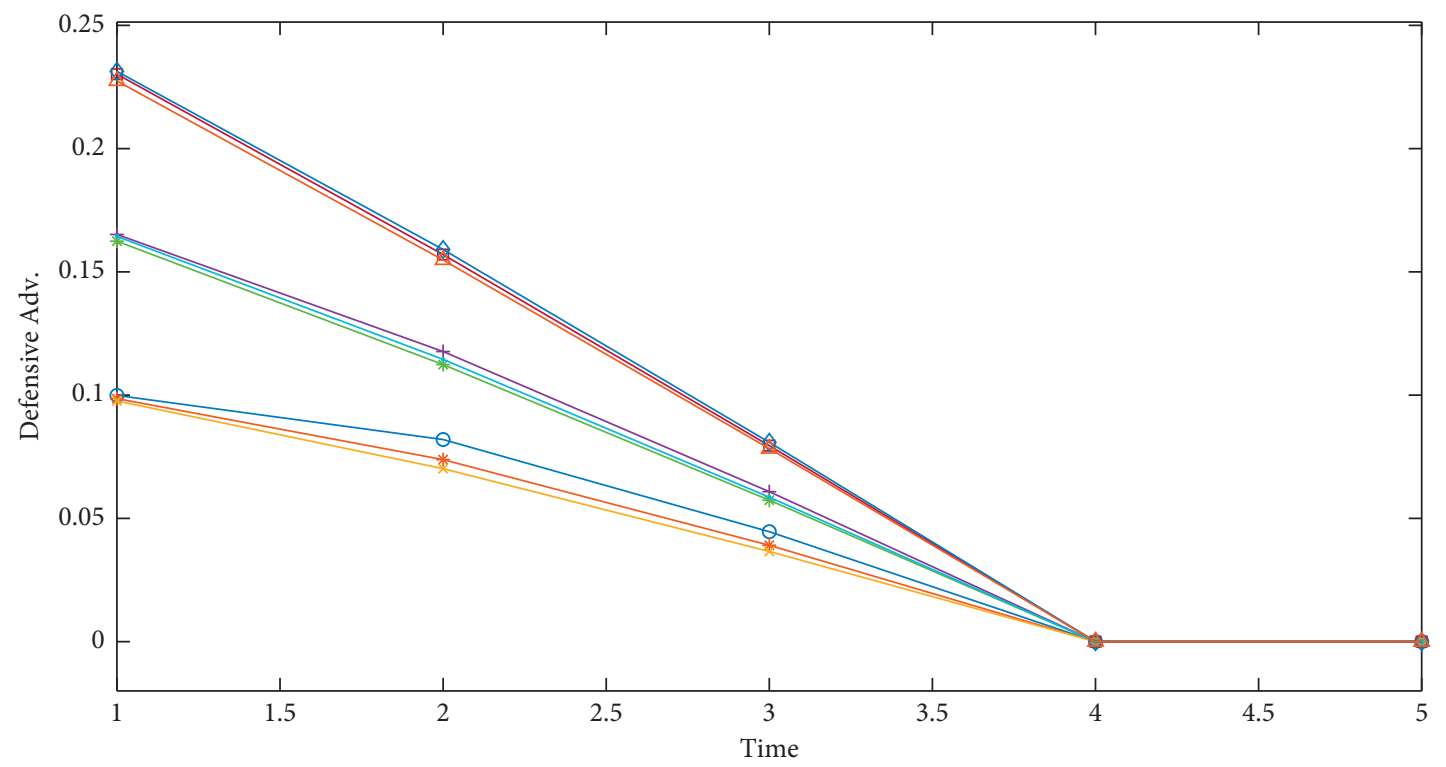

$\bigcirc \mathrm{M}_{1}=0.15, \mathrm{M}_{2}=0.15, \mathrm{M}_{3}=0.15$

* $\mathrm{M}_{1}=0.15, \mathrm{M}_{2}=0.25, \mathrm{M}_{3}=0.25$

$\rightarrow \mathrm{M}_{1}=0.15, \mathrm{M}_{2}=0.35, \mathrm{M}_{3}=0.35$

$+\mathrm{M}_{1}=0.25, \mathrm{M}_{2}=0.15, \mathrm{M}_{3}=0.25$

$\rightarrow-\mathrm{M}_{1}=0.25, \mathrm{M}_{2}=0.25, \mathrm{M}_{3}=0.35$

- $\mathrm{M}_{1}=0.25, \mathrm{M}_{2}=0.35, \mathrm{M}_{3}=0.15$

—- $\mathrm{M}_{1}=0.35, \mathrm{M}_{2}=0.15, \mathrm{M}_{3}=0.35$

$\neg \mathrm{M}_{1}=0.35, \mathrm{M}_{2}=0.25, \mathrm{M}_{3}=0.15$

$\triangle \mathrm{M}_{1}=0.35, \mathrm{M}_{2}=0.35, \mathrm{M}_{3}=0.25$

(b)

Figure 8: Continued. 


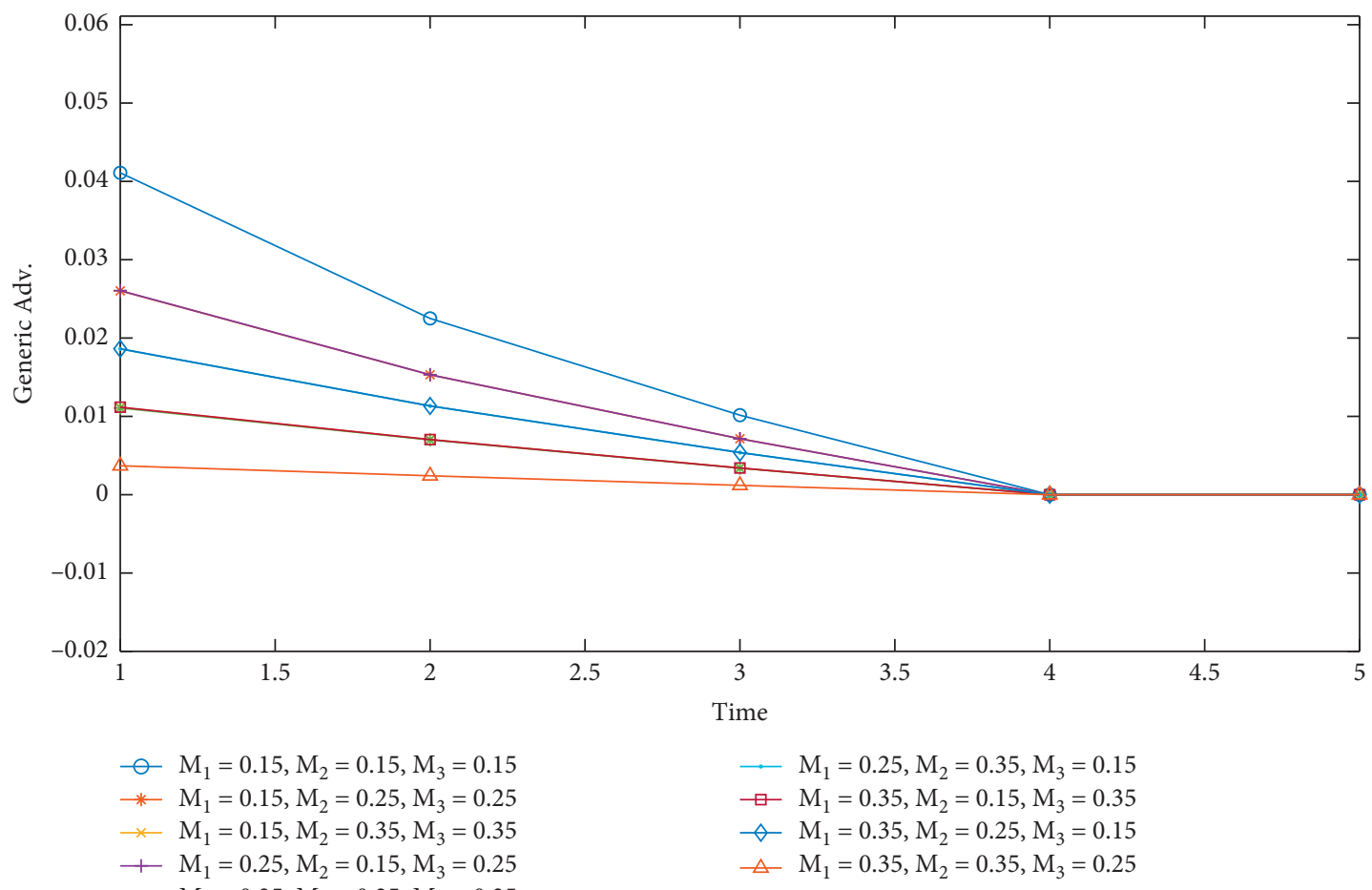

(c)

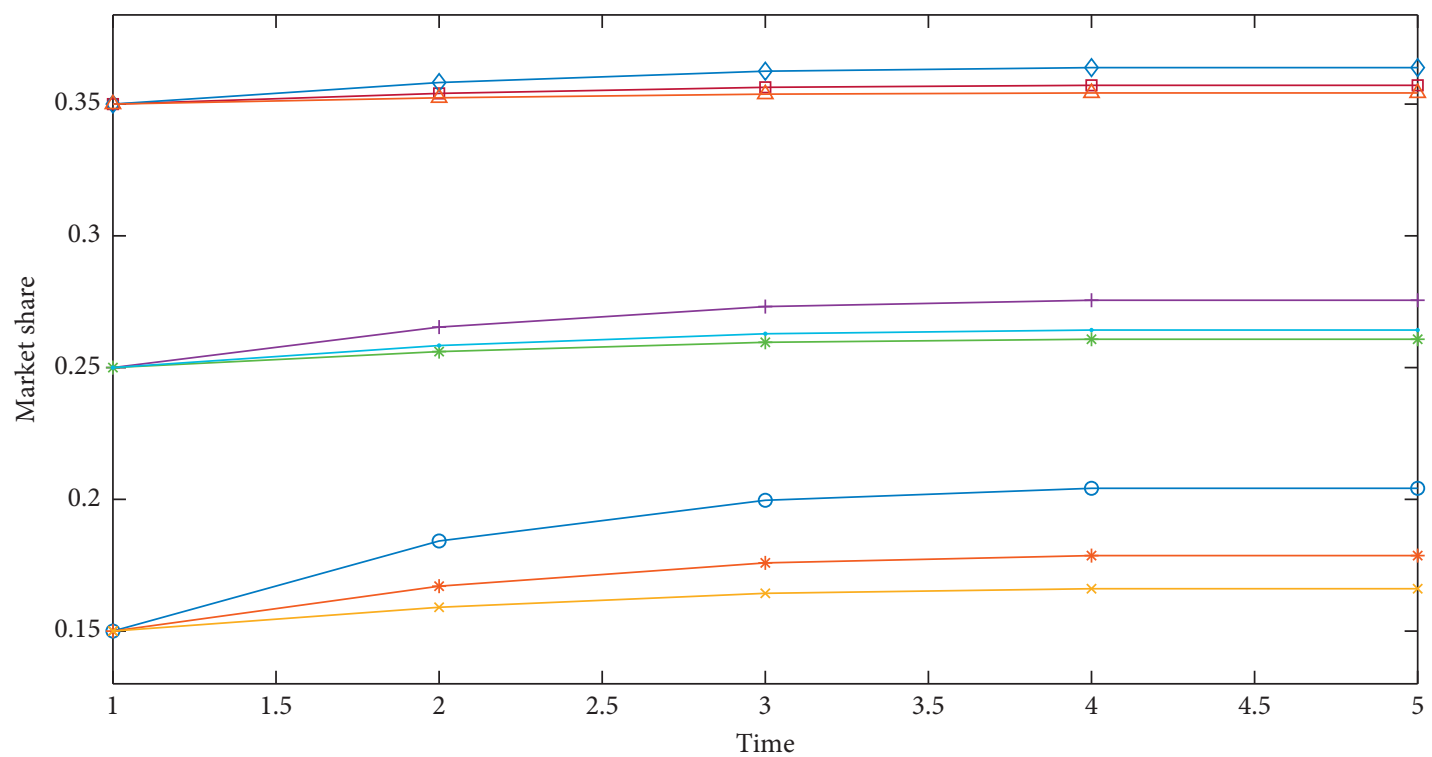

$\bigcirc \mathrm{M}_{1}=0.15, \mathrm{M}_{2}=0.15, \mathrm{M}_{3}=0.15$

$\rightarrow \mathrm{M}_{1}=0.15, \mathrm{M}_{2}=0.25, \mathrm{M}_{3}=0.25$

$\star \mathrm{M}_{1}=0.15, \mathrm{M}_{2}=0.35, \mathrm{M}_{3}=0.35$

$\longrightarrow \mathrm{M}_{1}=0.25, \mathrm{M}_{2}=0.15, \mathrm{M}_{3}=0.25$

* $\mathrm{M}_{1}=0.25, \mathrm{M}_{2}=0.25, \mathrm{M}_{3}=0.35$

$\therefore \mathrm{M}_{1}=0.25, \mathrm{M}_{2}=0.35, \mathrm{M}_{3}=0.15$

- $\mathrm{M}_{1}=0.35, \mathrm{M}_{2}=0.15, \mathrm{M}_{3}=0.35$

$\neg \mathrm{M}_{1}=0.35, \mathrm{M}_{2}=0.25, \mathrm{M}_{3}=0.15$

$\triangle \mathrm{M}_{1}=0.35, \mathrm{M}_{2}=0.35, \mathrm{M}_{3}=0.25$

(d)

FIGURE 8: Equilibrium trajectory changes due to initial market share changes for company 1. 
increased, and the level of defensive and generic advertising decreased.

\section{Conclusion}

In this paper, a Lanchester advertising model is developed in which companies find their offensive, defensive, and generic equilibrium advertising strategies in an asymmetric oligopolistic advertising competition. Previous research focusing on modeling offensive, defensive, and generic advertising strategies has been modeled in a symmetric duopoly game, although in reality, most advertising competitions are oligopoly and asymmetric. The proposed model is solved numerically in a triopoly market based on the hypothetical values of the parameters and the changes of different parameters are evaluated on the strategies of each company.

Marketing managers can use the model and approach of the solution proposed in this article as a decision support system to determine offensive, defensive, and generic strategies dynamically. Because in an asymmetric oligopoly game model, there are many parameters for each player, the model parameters can be dynamically determined based on current market conditions, and the rate of decrease or increase of strategic advertising efforts can be determined based on changes in competitors' strategies. In addition, by considering different scenarios for each parameter, future strategies can be predicted based on changes in competitors' strategies similar to the proposed approach for model sensitivity analysis.

This present model can be extended in several directions. The basic model of the advertising game in this research is the Lancaster model. One possible development is the use of other advertising competition models such as the Nerlov and Arrow [22], Vidale and Wolfe [23], and Diffusion [24] with considering offensive, defensive, and generic advertising strategies in the oligopolistic market. Another interesting problem is considering the customer's recommendation to change the market share of companies neglected in this research. Also, determining equilibrium strategies in the offensive, defensive, and generic in a segmented market can be considered grounds for future research.

\section{Data Availability}

The data models used are stated in the reference section of the publication and the data used throughout the paper were derived from operational data generated at three companies, Snap, Carpino, and Tap30. These are actual data in which the said companies made available to be used towards this study.

\section{Conflicts of Interest}

The authors declare that they have no conflicts of interest.

\section{References}

[1] S. Saha, D. Chatterjee, and B. Sarkar, "The ramification of dynamic investment on the promotion and preservation technology for inventory management through a modified flower pollination algorithm," Journal of Retailing and Consumer Services, vol. 58, Article ID 102326, 2021.

[2] B. Sarkar, M. Omair, and N. Kim, "A cooperative advertising collaboration policy in supply chain management under uncertain conditions," Applied Soft Computing, vol. 88, Article ID 105948, 2020.

[3] W. Shen, H. Gu, L. J. Ball et al., "The impact of advertising creativity, warning-based appeals and green dispositions on the attentional effectiveness of environmental advertisements," Journal of Cleaner Production, vol. 271, Article ID 122618, 2020.

[4] G. Kim and I. Moon, "Online banner advertisement scheduling for advertising effectiveness," Computers \& Industrial Engineering, vol. 140, Article ID 106226, 2020.

[5] M. Parlar, "Feedback advertising strategies in a two-firm differential game: a numerical investigation," International Journal of Systems Science: Operations \& Logistics, vol. 7, pp. 1-12, 2020.

[6] N. Hamelin, O. E. Moujahid, and P. Thaichon, "Emotion and advertising effectiveness: a novel facial expression analysis approach," Journal of Retailing and Consumer Services, vol. 36, pp. 103-111, 2017.

[7] S. Jørgensen and S.-P. Sigué, "Defensive, offensive, and generic advertising in a Lanchester model with market growth," Dynamic Games and Applications, vol. 5, no. 4, pp. 523-539, 2015.

[8] A. Garai, S. Chowdhury, B. Sarkar, and T. K. Roy, "Cost-effective subsidy policy for growers and biofuels-plants in closed-loop supply chain of herbs and herbal medicines: an interactive biobjective optimization in T-environment," Applied Soft Computing, vol. 100, Article ID 106949, 2021.

[9] M. Pervin, S. K. Roy, and G.-W. Weber, "Analysis of inventory control model with shortage under time-dependent demand and time-varying holding cost including stochastic deterioration," Annals of Operations Research, vol. 260, no. 1-2, pp. 437-460, 2018.

[10] G. M. Erickson, "Offensive and defensive marketing: closedloop duopoly strategies," Marketing Letters, vol. 4, no. 4, pp. 285-295, 1993.

[11] G. Martín-Herrán, S. McQuitty, and S. P. Sigué, “Offensive versus defensive marketing: what is the optimal spending allocation?" International Journal of Research in Marketing, vol. 29, no. 2, pp. 210-219, 2012.

[12] D. Machowska, "Investigating the role of customer churn in the optimal allocation of offensive and defensive advertising: the case of the competitive growing market," Economics and Business Review, vol. 4 (18), no. 2, pp. 3-23, 2018.

[13] D. Machowska and A. Nowakowski, "Competition in defensive and offensive advertising strategies in a segmented market," European Journal of Control, vol. 53, pp. 98-108, 2019.

[14] G. M. Erickson, "A differential game model of the marketingoperations interface," European Journal of Operational Research, vol. 211, no. 2, pp. 394-402, 2011.

[15] F. El Ouardighi, S. Jørgensen, and F. Pasin, "A dynamic game of operations and marketing management in a supply chain," International Game Theory Review, vol. 10, no. 4, pp. 373-397, 2008.

[16] G. M. Erickson, Dynamic Models of Advertising Competition, Kluwer Academic Publishers, Boston, MA, USA, Second edition, 2003.

[17] R. Isaacs, Differential Games, a Mathematical Theory with Applications to Optimization, Control and Warfare, Wiley, New York, NY, USA, 1965. 
[18] D. W. Yeung and L. A. Petrosjan, Cooperative Stochastic Differential Games, Springer Science \& Business Media, Berlin, Germany, 2006.

[19] L. S. Pontryagin, "On the theory of differential games," Russian Mathematical Surveys, vol. 21, no. 4, pp. 193-246, 1966.

[20] G. M. Erickson, Dynamic Models of Advertising Competition, Springer Science \& Business Media, Berlin, Germany, 2012.

[21] L. Brugnano, F. Iavernaro, and D. Trigiante, "Analysis of Hamiltonian Boundary Value Methods (HBVMs): a class of energy-preserving Runge-Kutta methods for the numerical solution of polynomial Hamiltonian systems," Communications in Nonlinear Science and Numerical Simulation, vol. 20, no. 3, pp. 650-667, 2015.

[22] M. Nerlove and K. J. Arrow, "Optimal advertising policy under dynamic conditions," Economica, vol. 29, no. 114, pp. 129-142, 1962.

[23] M. L. Vidale and H. B. Wolfe, "An operations-research study of sales response to advertising," Operations Research, vol. 5, no. 3, pp. 370-381, 1957.

[24] F. M. Bass, "A new product growth for model consumer durables," Management Science, vol. 15, no. 5, pp. 215-227, 1969. 